\title{
An oil risk management system based on high-resolution hazard and vulnerability calculations
}

\author{
Alberto Azevedo ${ }^{\mathrm{a},{ }^{*}}$, André B. Fortunato ${ }^{\text {a }}$, Bruno Epifânio ${ }^{\mathrm{a}}$, Sérgio den Boer ${ }^{\text {a }}$, Eduardo \\ R. Oliveira ${ }^{\mathrm{b}}$, Fátima L. Alves ${ }^{\mathrm{b}}$, Gonçalo de Jesus ${ }^{\mathrm{a}}$, João L. Gomes ${ }^{\mathrm{a}}$, Anabela Oliveira ${ }^{\mathrm{a}}$ \\ a National Laboratory for Civil Engineering, Av. do Brasil 101, 1700-066 Lisbon, \\ Portugal \\ ${ }^{b}$ Department of Environment and Planning \& CESAM, University of Aveiro, Campus \\ Universitário de Santiago, 3810-193 Aveiro, Portugal \\ * Corresponding author. Tel.: +351 218443758; Fax: +351 218443016 \\ E-mail address: aazevedo@lnec.pt (Alberto Azevedo)
}

Ref.:

Alberto Azevedo, André B. Fortunato, Bruno Epifânio, Sérgio den Boer, Eduardo R. Oliveira, Fátima L. Alves, Gonçalo de Jesus, João L. Gomes, Anabela Oliveira, An oil risk management system based on highresolution hazard and vulnerability calculations, Ocean \& Coastal Management, Volume 136, February 2017, Pages 1-18, ISSN 0964-5691, http://dx.doi.org/10.1016/j.ocecoaman.2016.11.014.

URL: http://www.sciencedirect.com/science/article/pii/S0964569116303015

Available online: 15 November 2018 
Abstract

A new oil risk management system is proposed herein. Risk is computed in a quantitative way, combining a detailed hazard maps generated with a process-based oil spill model over an unstructured computational grid, and a spatially detailed methodology for vulnerability analysis. The system has a web interface that serves as a single point of access to both emergency-driven and risk-management products. The system's products are made available to decision makers and emergency response agents through a WebGIS portal. The paper describes the methodological bases and application of a risk-assessment tool that provides hazard, vulnerability and risk assessment maps for oil spills in coastal areas.

The system is demonstrated in the Aveiro lagoon. The hazard maps are obtained from the analysis of an oil spill scenarios database, generated for the climatological conditions most prone to the occurrence of an oil spill event in the study region. Several vulnerability indexes are considered (namely physical, socio-economical, biological and global vulnerability indexes) and adapted to consider the intertidal areas, instead of the commonly-used coastline representation of the vulnerability indexes usually found in the literature. This new feature was possible due to the capability of the oil spill model to represent the process of oil retention and re-suspension in the intertidal zones.

The methodology and the risk management system and its WebGIS interface are of generic nature and can be applied to other hazards in coastal zones.

Keywords:

Quantitative risk analysis, high-resolution oil spill model, unstructured grid, spatial vulnerability analysis, coastal zones, Aveiro lagoon 


\section{Introduction}

The potentially devastating consequences of accidental oil and chemical spills on the coastal environment raise a growing concern on the preparedness and response to spillinduced emergencies. This concern fuelled the implementation of several support tools, including pollution monitoring systems (Kingston, 2002; de la Huz et al., 2005; PenelaArenaz et al., 2009) and modelling systems (Abascal et al., 2007; Azevedo et al., 2009, 2014; Wang and Shen, 2010; Liu et al., 2013). However, in the event of a spill accident that affects coastal resources, each tool is mostly used in a disconnected, ad-hoc fashion, without compliance to the risk management cycle, and often not providing accurate predictions at the right scales due to computational constrains or unknown local conditions. Coastal pollution risk prevention is usually based on contingency plans (Sanchez, 2008; Lee and Jung, 2013), supported by studies mostly based on simplified tools, applied in simplified settings and often disregarding local environmental and socioeconomic conditions that may promote spill accidents and increase their impacts.

Risk management information technology systems were proposed to support planning and emergencies (Chrastanskya et al., 2009) and have been successfully applied to several risks, such as tsunamis (Careem et al., 2006), and dam-break (Rodrigues et al., 2002; Jesus et al., 2010) and coastal inundations (Fortunato et al., in review). These management systems can be used for oil pollution risks to provide an adequate framework for the effective protection of coastal resources. Their application to accidental oil spills requires adaptation on the phases of preparedness and response. To properly plan, through contingency plans, or to forecast spill accidents requires the ability to quantify the relevant environmental conditions that may promote accident occurrence at the adequate spatial scale, through data or numerical models, and to characterize accurately the relevant processes. Recent developments on the efficiency of high-resolution modelling systems for coastal problems using high-performance resources (Costa et al., 2009; Dietrich et al., 2012; Azevedo et al., 2014) paves the way to their application to pollution risk analysis.

The terminology and concepts broadly involved in risk assessment are however often ambiguous and even controversial in the scientific community, mainly due their extended use in different sciences and the lack of standardization. Only in recent years have authoritative agencies begun to compile the major vocabularies, such as hazard, vulnerability and risk (Christensen et al., 2003). The concept of hazard relates to the probability of occurrence of a natural or anthropogenic event within a given time period and affecting a specified area, and to the impact of this event on the environment or society (Cutter, 1993; UNDHA, 2002). This term is often defined as a threatening event (UNDHA, 2002) or a source of potential damage and possible risk source (ISO Guide 73, 2009), which may cause property damage, economic loss, environmental degradation or loss of human lives. Sources of hazard resulting from human activities that cause or 
enhance unexpected accidents (e.g. the spill of oil or other dangerous substances) are designated as technological hazards (Zêzere et al., 2008).

According to the International Organization for Standardization (ISO Guide 73, 2009), vulnerability is the intrinsic property of the exposed elements that derives from their susceptibility to a risk source, which can lead to an event with a negative consequence. This term can also be defined as the expected degree of loss of exposed elements resulting from a potentially damaging event (UNDHA, 2002; Kumpulainen, 2006; Schmidt et al., 2011). Simultaneously, this term can be associated with the susceptibility and resilience of the exposed elements to negative impacts from hazardous events (NOAA, 1999, mentioned in Andrade et al., 2010). Thus, vulnerability depends not only on the resistance of the exposed elements to the potential damage, but also on the resilience of those elements after the occurrence of the event (Salter, 1997; Kleissen et al., 2007; Lahr and Kooistra, 2010).

The concept of risk can be understood as the expected losses due to the occurrence of the adverse event for a given time period and specified area, that result from the interaction between the natural or anthropogenic hazard and the vulnerable assets (UNDHA, 2002; De-Lange et al., 2010). Additionally, other authors (Ansell and Wharton, 1992; Tarrant, 1998; ISO Guide 73, 2009; Lee and Jung, 2013) define risk as the product between the likelihood associated with the occurrence of the events and the consequences on the exposed elements, often estimated by hazard and vulnerability, respectively - an approach conceptually appropriate and widely accepted (De-Lange et al., 2010; UNDHA, 2002; Xiaoyan and Xiaofei, 2012). Some studies (e.g. Schwab et al., 1998; Douglas, 2007; Garcia et al., 2013) consider the inclusion of another term in the expression: the exposure of elements. This term can be described by several indicators such as the duration of exposure or the concentration or type of substance whose presence promotes danger (Kleissen et al., 2007).

Risk assessment, one of the stages of risk management, involves identifying how exposed elements may be affected and the probability of occurrence of these adverse effects (ISO/IEC 31010). Within oil spill risk assessments, many researchers have targeted several themes: the marine pollution (e.g. Grifoll et al., 2010; Olita et al., 2012; Liu et al., 2013), the harbour areas (e.g. Rao and Raghavan, 1996; Trbojevic and Carr, 2000; Ronza et al., 2006) and the maritime transportation (e.g. Iakovou, 2001; Eide et al., 2007; van Dorp and Merrick, 2011), following very diverse approaches.

According to van Westen et al. (2006), risk assessment methods can be split into three categories: (i) quantitative methods - which determine the probability and consequences of possible loss or damage in numerical and quantitative terms; (ii) qualitative methods based on an expert opinion to estimate the probability and consequences of potential loss or damage in qualitative terms; and (iii) semi-quantitative methods - which combine quantitative methods (when possible) with qualitative methods. While quantitative 
methods are the most appropriate and practical approach to risk assessment, applying them to all exposed elements and sources of hazard remains impossible in many cases (EcoRA, 2013). Semi-quantitative methods are thus often a good viable alternative. Although these methods are more subjective, they may be sufficient and suitable to risk assessment depending on the decisions to be taken and the resources available (EcoRA, 2013; IPIECA, 2013). The method to be used should be chosen in accordance with the purpose and nature of the problem and the quality and quantity of data that are available for the risk analysis (Dai et al., 2002; Zêzere and Garcia, 2013).

Several risk assessment studies based on quantitative methods can be referenced. Griffol et al. (2010) focus on the degradation of the water quality in harbour areas. These authors developed a method for environmental risk assessment that determines risk using indexes that reflect different issues, such as the substance of a potential spill, the probability of occurrence of the events, and the water currents and renewal in the harbour area. Regarding oil spill risk assessment applied to coastal areas, Olita et al. (2012) also developed a methodology based on hazard and vulnerability indexes determined from concentrations of oil at two different times and places and from two vulnerability factors: the beaches geomorphology and the level of protection for the areas under study. Liu et al. (2013) determined the risk of environmental pollution using a hierarchical system of indexes with four levels. The risk index was determined directly from hazard and vulnerability indexes, based on a set of sub-indexes referring the risk source state, the precautionary source control of risk, the effectiveness of precautionary progress control, the exposure levels experienced by people and ecosystems, and the local adaptive capacity to potential pollution accidents. On a more conceptual and comprehensive perspective, Santos et al. (2013) developed an operational model based on the link between marine spatial planning (MSP) and oil spill risk analysis (OSRA), by analysing the key processes and identifying commonalities between both methodologies, MSP and OSRA. These authors propose that oil spill risk analyses estimate the environmental and socio-economic values and the extent of the damage that a spill may represent to a specific area. Kleissen et al. (2007), in the context of a marine environmental risk assessment for the Dutch continental shelf, identified marine areas under high environmental risk associated with the oil transport in the North Sea, and developed methodologies and tools that allowed the assessment of oil spill and other hazardous materials environmental risk.

The qualitative methodologies, which are usually associated with the use of risk matrices, can be illustrated by the work developed by Lee and Jung (2013) on risk assessment and on a national plan for spills, accidents with oil and dangerous substances that occurred between 1994 and 2005 near Korea. In this study, the risk matrices were created based on the relation between the frequency and the severity of the accidents, which depended on the substance and spill volumes. IPIECA (2013) provided guidance and recommendations for the implementation of effective risk assessment and oil spill response planning associated with the installation of oil and gas, taking into account the 
likelihood of hydrocarbon offshore spills and also the potential environmental and socioeconomic consequences that could result from these accidents. These qualitative methodologies consider that the risk matrix assessment is suitable for early project stages when the available information is usually limited.

A novel, quantitative oil risk management system is proposed herein, taking advantage of the availability of recent developments in comprehensive oil spill models (Tkalich, 2006; Azevedo et al., 2014), combined with the general availability of large computational resources. These oil models fully account for the relevant oil processes at the adequate time scales for local risk analysis. The model used herein, VOILS (Azevedo et al., 2014), provides in particular a detailed approach to the retention and re-suspension of oil in intertidal areas, accounting for specific bottom characteristics and oil type. It further guarantees oil mass conservation and a rigorous accountability for oil in water and in the bottom sediments. Risk is thus quantified with rigour, taking advantage of the fine hazard calculations, supported by a local meteo-ocean analysis and a spatially detailed vulnerability analysis of the area under study. Taking advantage of having an oil model that can represent the oil at the intertidal flats, which are the most sensitive areas under a spill influence, this vulnerability assessment accounts for the environmental, social and physical effects over the entire area at risk.

Oil spill forecast systems have been proposed recently (e.g Castanedo et al., 2009, Fernandes et al., 2015), taking advantage of operational oceanography modelling systems, but the combination of these with high accuracy, process-based oil models (such as those proposed in Tkalich, 2006 and Azevedo et al., 2014) and detailed vulnerability assessment approaches have not been proposed yet. Innovation is also achieved here by integration of the risk system products within an WebGIS portal (improved from the one described in Oliveira et al., 2014), providing a single point of access to all relevant oil spill risk information (planning and emergency) for decision makers and emergency response agents. Together with the more conventional integrated risk management products, the proposed management system provides a full range support for all activities in a multiple uses coastal system. The usefulness is demonstrated here for the Aveiro lagoon, a coastal lagoon that includes environmentally protected areas and many familyrun lagoon-based businesses, along with several large maritime industries, of which the Port of Aveiro is the most prominent.

The current legislation in Europe promotes the vision of integrated risk management products and creates the context for the adoption of tools such as those proposed herein for territory management. Indeed, as a result of the implementation of the European Water Framework Directive, water resources have become a central element of the process of territorial planning and regulation in Europe. According to this legal framework, the integration of the risk component is required for territorial management instruments, within the multiple sectors of activity, and different dimensions of governance - local, 
regional and national - in order to facilitate the cooperation between different instruments of territorial management, enhancing risk valuation, qualification and development in physical, social and economic terms.

Organizations with responsibilities in maritime safety have promoted many initiatives to minimize maritime accidents through investments in safer ships, better crew training and improved practices and regulations that take into account the need to preserve the marine environment. The International Convention for the Prevention of Pollution from Ships (MARPOL) is the main international convention, which includes regulations aimed at preventing and minimizing the pollution of marine environment by ships from operational or accidental causes. Nevertheless, globalization remains particularly dependent on shipping, which is used to transport almost every type of tradable goods. As a consequence, global seaborne trade continues to grow, creating additional hazards for ships, seafarers and the environment.

After the present literature review on oil spill risk analysis and clarification of some key concepts on risk assessment, the next Section describes the methods developed to evaluate the hazard, the vulnerability and the risk. These methods are illustrated in Section 3 through the application to a sensitive coastal system (Aveiro lagoon, Portugal). Section 4 discusses the results obtained for the Aveiro lagoon. Section 5 focuses on the major contributions of the presented methodology and respective application to the Aveiro lagoon to the improvement of the state-of-the-art in oil spill risk assessment. This section also presents the products that can be delivered to the coastal management authorities. Finally, the main conclusions are summarized in section 6.

\section{Methodology}

\subsection{Hazard Assessment}

The hazard is computed based on the analysis of an oil spill scenarios database, which is built accounting for the climatological conditions of the study region, the historical records of past oil spill events and the expert judgment on the most likely locations for the occurrence of an oil spill inside the area of interest (Fig. 6: Location of the six oil spill sites in the Aveiro's Harbour jurisdiction area.Fig. 6Error! Reference source not found.). The database consists in a set of oil spill simulations, corresponding to a set of predefined, most frequent climatological scenarios, assigned with a probability of occurrence. The hazard methodology follows four steps. First, past oil spill occurrences in the study area are analyzed to determine the most favorable weather and ocean conditions for this type of event. Then, the climatological conditions for the main forcings (wind, tides and waves typically) are estimated for the study area. This analysis is performed from databases of past environmental conditions in the region (from hindcasts or measured data), constrained by the information determined in the first step. This task defines the climatological conditions propitious to the occurrence of spill accidents and 
their associated probabilities. In the third step, a database of hydrodynamic simulations is generated, taking in consideration the results from the previous step. Finally, a database of oil spill simulations is generated for each predefined spill location, release time in the tidal cycle and hydrodynamic condition determined in step 3 . The final product is an oil spill scenarios database with associated probabilities of occurrence for a particular location. Details on the hazard determination and its application to the Aveiro lagoon are provided in den Boer et al. (2014).

\section{$<$ FIGURE 1>}

Fig. 1: Hazard index definition scheme.

\subsection{Vulnerability Assessment}

The vulnerability assessment methodology considered in this paper is based on the proposal of Oliveira et al. (2013), enhanced herein with several changes on the index structure. A global vulnerability index is thus obtained from the balance of three specific indexes, for physical, biological and socio-economic aspects, which can be applied to either shoreline, intertidal, or subtidal areas (Fig. 2).

The Physical Index, $I_{P}$, ranges between 1 and 10, considering whether there are subtidal, intertidal or shoreline conditions, as well as other aspects such as exposure, substrate type or shoreline slope, which are based on the guidelines of the Environmental Sensitivity Index (Petersen et al., 2002).

The Biological Index, $I_{B}$, is based on the definition from Oliveira et al. (2013), with an additional condition for its maximum score, corresponding to the occurrence of threatened species of fauna or flora (with vulnerable, endangered, endemic or protection status). Like the Physical Index, the Biological Index ranges between 1 and 10 .

The Socio-Economic Index, $I_{S E}$, is determined according to the Polmar plans methodology, a national sensitivity atlas of the French coast (e.g. CEDRE, 2005) which includes an economic sensitivity index based on the duration of the interruption of activities during oil spill events. This index accounts for multiple groups of activities, such as industry, transport, recreation, commerce, or resource extraction. The SocioEconomic Index ranges between 0 and 5, depending on whether this duration is of the order of days, months, or years.

The Global Vulnerability Index, $I_{G}$, is given by (Eq.1), considering the range of values of these three indexes by equally distributing their importance. The global vulnerability results are classified according to four classes - 'very low', 'low', 'medium' and 'high' - depending on $I_{G}$, which varies from 0 to 3 . 


$$
I_{G}=\frac{I_{P}-1}{9}+\frac{I_{B}-1}{9}+\frac{I_{S E}}{5}
$$

\section{$<$ FIGURE 2>}

Fig. 2: Scheme of the vulnerability indexes used in the present study.

\subsection{Risk Assessment}

The oil risk management system proposed herein is based on a quantitative approach that takes advantage of accurate oil spill models and high-resolution vulnerability analyses. Oil models fully account for the relevant oil processes solving for the adequate time scales for local risk analysis. The model used herein, VOILS (Azevedo et al., 2014), simulates in particular the retention and re-suspension of oil in intertidal areas, accounting for specific bottom characteristics and oil type. Oil mass is conserved and the partition of oil between the water and the bottom sediments is determined.

The accuracy and detailed analysis provided by the proposed management system also benefits from a spatially-fine vulnerability analysis. In this analysis, a modified approach to vulnerability is proposed that handles in detail the conflicting impacts of oil spills in harbour facilities located near valuable environmental resources and the limitations of traditional spill response devices in highly dynamic channels. These factors are properly inserted in the vulnerability classification and provide an accurate support to risk calculations. Additionally, the proposed methodology goes beyond the traditional coastal margin (line) classification (e.g., Castanedo et al., 2009) to account for vulnerability to oil spills in intertidal flats and channels, addressing the impacts on shellfish farms and other assets located in these areas. Herein we illustrate the impact of the inclusion of the oil retention process along the intertidal flats in the vulnerability results through the case study - Aveiro lagoon (the development of the vulnerability analysis is described in detail in Oliveira et al., 2013).

Risk is computed in a rigorous, quantitative way, taking advantage of the detailed hazard calculations, supported by local metocean analysis (den Boer et al., 2014), and a spatially detailed vulnerability analysis (Fig. 3). Nevertheless, a qualitative aspect remains as the oil spill locations for the region under study are determined by expert judgement of the relevant authorities. Rather than blindly considering all possible geographical locations for the spill within the area of interest, the expert knowledge that accounts for the ship routes and the local characteristics of the harbour is included in the methodology for efficiency and faster access to hazard calculations.

Instead of just integrating all the information within a single map, risk is analysed under distinct perspectives to provide a comprehensive management tool: 1) distinct aspects of 
vulnerability (physical, ecological and socio-economic) are identified in risk maps, providing scientific support for risk mitigation decisions, targeted at the specific aspects of risk; 2) distinct potential accident zones are individualized to support port management plans and improve/revise the associated contingency measures; 3) tidal phase distinction is associated with risk to support the choice of areas to be protected in a prioritized fashion as well as the choice of the adequate response devices.

\section{$<$ FIGURE 3>}

Fig. 3: Risk assessment definition scheme.

3. Case study: a quantitative oil risk management system for the Aveiro lagoon

Herein we illustrate the proposed methodology for oil spill risk, vulnerability and hazard calculation through an application to the Aveiro lagoon. This deployment is currently available for the Port of Aveiro authorities through a WebGIS portal (Oliveira et al., 2014). The next sub-sections present each of the methodological steps in detail, after a brief overview of the relevant characteristics of this coastal system.

Located in the North-Western Portuguese coast ( $40^{\circ} 38^{\prime} \mathrm{N}, 8^{\circ} 45^{\prime} \mathrm{W}$ ), the Aveiro lagoon (Fig. 4) is a shallow coastal lagoon with a length of $45 \mathrm{~km}$ (N-S direction) and a maximum width of $10 \mathrm{~km}$ (W-E direction). The Aveiro lagoon is separated from the Atlantic Ocean by a sand dune barrier interrupted by a single jettied tidal inlet about $1.3 \mathrm{~km}$ long.

\section{$<$ FIGURE 4>}

Fig. 4: Location and bathymetry of the Aveiro lagoon.

The Aveiro lagoon has many narrow channels and extensive intertidal areas, mainly mudflats, salt marches and old salt pans (Picado et al., 2010). The lagoon system radiates from the sea entrance along four main branches with irregular geometries: S. Jacinto, Espinheiro, Mira and Ílhavo channels. The average depth of the lagoon is $1 \mathrm{~m}$ (Lopes and Dias, 2007). The lagoon is surrounded by low-lying lands: the zone between 0 and $4 \mathrm{~m}$ above mean sea level has an area of about $160 \mathrm{~km}^{2}$ (Fortunato et al., 2013).

Tide is the most important forcing agent of the circulation in the Aveiro lagoon (Lopes and Dias, 2007). Near the inlet, tides are mainly semi-diurnal and the lagoon is mesotidal, with a mean tidal range of about of $2 \mathrm{~m}$ at the inlet, varying between 0.6 and $3.2 \mathrm{~m}$ during neap and spring tides, respectively (Dias et al., 2000). The lagoon area varies between 66 
and $83 \mathrm{~km}^{2}$ at low and high spring tide, respectively (Dias and Lopes, 2006). At the tidal inlet, the tidal prism varies between $35 \times 10^{6}$ and $137 \times 10^{6} \mathrm{~m}^{3}$, with a mean of about $70 \times 10^{6}$ $\mathrm{m}^{3}$ (Dias and Lopes, 2006).

The wind stress and the freshwater discharges also influence the lagoon hydrodynamics. The several rivers that flow into the Aveiro lagoon discharge about $1.8 \times 10^{6} \mathrm{~m}^{3}$ of freshwater during a tidal cycle. The major sources of freshwater are the rivers Vouga and Antuã, which discharge into the Espinheiro channel (Dias and Lopes, 2006). The residence time in the lagoon ranges between less than 2 days near the inlet and more than 1 week in the upstream areas of the channels (Dias et al., 2001).

The Aveiro lagoon includes relevant ecosystems for multiple species of fauna and flora, but also plays a significant role for the local economy and communities. Besides its unique ecological characteristics, this system is fundamental for the agriculture and aquaculture sectors, leisure and recreational activities, and tourism, also hosting the infrastructures of the Port of Aveiro and several small traditional shipping harbours (Alves et al., 2011). The occurrence of multiple uses and activities originates anthropic pressures over the lagoon and conflicts between them and the natural environment. This lagoon is highly vulnerable to oil spills, given its rich biodiversity and fragile ecosystems, recognized as a Special Protection Area according to the Natura 2000 network. In 2014 it was integrated in the National Protected Areas list.

\section{Results}

\subsection{Hazard Assessment}

\subsubsection{Analysis of past oil spill accidents}

An oil spill database from DGAM (Direção Geral da Autoridade Marítima), the national maritime authority in Portugal, was analysed to characterize the past oil spill events in the Aveiro lagoon. This database contains records of spills that occurred between 1971 and 2011 along the Portuguese jurisdiction area and additional information about the events (e.g. place and origin of spill events and typology, and volume of substance spilled). Overall, 2075 oil spill events were recorded: 400 in the Northern region of Portugal, 1192 in the Central region of Portugal, 93 in the Southern region of Portugal, 92 in the autonomous region of the Azores, 78 in the autonomous region of Madeira, and 220 over the remaining Exclusive Economic Zone of Portugal.

During these 40 years, 73 oil spill events were recorded in the Aveiro lagoon, with a high inter- and intra-annual variability (Fig. 5). The records are particularly relevant in the time period between 1985 and 2006 during which 63 events occurred $(86.3 \%$ of the total number of events) (Fig. 5). 


\section{<FIGURE 5>}

Fig. 5: Inter-annual variability of the oil spills occurred between 1971 and 2011 in the Aveiro lagoon.

Most of the spill events in the Aveiro lagoon originate from vessels (34.2\%), fishing boats $(28.8 \%)$ and businesses $(17.8 \%)$. Considering only the events with information on the spill volume (33 out of the 73 events), the vessels and the fishing boats are the sources that cause the largest spills (in total $2.885 \mathrm{~m}^{3}$ and $3.26 \mathrm{~m}^{3}$ respectively), corresponding to $94.5 \%$ of the 33 spill events in the Aveiro lagoon. Oily substances (e.g. oil and oily wastes) and diesel are the two main pollutants spilled in the Aveiro lagoon (in total 2.408 $\mathrm{m}^{3}$ and $9.66 \mathrm{~m}^{3}$ respectively).

The weather conditions most favourable for the occurrence of accidental oil spills caused by ship accidents along the Portuguese coast were determined from the historical spill records from both DGAM and CEDRE (Centre of Documentation, Research and Experimentation on Accidental Water Pollution) databases. The historical records show that only 35 occurrences were reported, along the Iberian Atlantic shelf for the fall and winter periods, between October and March. For oceanographic standardization purposes, a study period of three months (December, January and February) was considered, which includes about two thirds of the oil spill occurrences. Then, the wind speed and direction and the wave characteristics (significant wave height, peak period and wave direction) were analysed for all 35 historical spills through NCEP-GDAL and ERA-I global reanalysis project databases. The analysis of the climatological and historical spills records leads to a set of 192 hydrodynamic conditions, which were simulated and then used to run the oil spill simulations. For these simulation conditions three different tidal instants and six distinct oil spill locations were considered (Figure 6). The combination of these scenarios generated the final oil spill database, with 3456 oil spill scenarios for the Aveiro lagoon region. The next section focuses on the definition of the hazard calculations and maps, built from the oil spills scenarios database. Further details on the climatological analysis and the oil spills scenarios database construction can be found in den Boer et al. (2014).

\subsubsection{Hazard quantification}

4.1.2.1. Coupled hydrodynamic simulation of waves and currents

A scenarios database with the specific environmental conditions and their probabilities is essential to the present oil hazard quantification. Firstly, the threshold environmental conditions for the occurrence of ship accidents were established, according to the magnitude of wind speed and significant wave height at the time of accidents. From this 
analysis, the wind threshold value below which no accidents are expected to occur was defined as $3.0 \mathrm{~m} / \mathrm{s}$ because the minimum wind speed present in the database is $3.9 \mathrm{~m} / \mathrm{s}$. Similarly, the significant wave height threshold was set to $4 \mathrm{~m}$ because the accidents that occurred for wave heights lower than $4 \mathrm{~m}$ were originated by other causes such as engine failure, fires or collisions during fog events. Thus, a scenarios database of a set of environmental conditions (defined by five variables: wind speed, wind direction, significant wave height, mean wave direction and mean wave period) was created with only the elements in which wind speed or the significant wave height are higher than the threshold values for a time period between December and February.

To determine the probability associated with each 5-dimensional bin, the continuum range of each environmental condition was discretized into three percentiles intervals: $0^{\text {th }}$ $-75^{\text {th }} ; 75^{\text {th }}-95^{\text {th }}$; and $95^{\text {th }}-100^{\text {th }}$. Bins were ranked according to this probability and a representative value was determined for each bin by averaging all elements of the subset in the bin for each of the five variables. All bins that did not include any occurrence were eliminated. Three tidal ranges representative of spring, neap and mean tides were considered (Table 3), and their probabilities were determined based on data from the Aveiro coast.

A set of 192 hydrodynamic simulations were considered, corresponding to 64 wind and wave conditions and three tidal amplitudes (den Boer et al., 2014). These simulations were run using the shallow water model ELCIRC (Zhang et al., 2004) and the wave model SWAN (Booij et al., 1999), coupled through the morphodynamic modeling system MORSYS2D (Bertin et al., 2009, Bruneau et al., 2011, Fortunato et al., 2014) under fixed bathymetry conditions. The coupling includes both the effect of varying tidal elevation on wave propagation, and the generation of littoral currents by waves. The latter process is crucial to move the oil plume away from the inlet on ebb, reducing its reentrance in the lagoon on flood. Each simulation corresponds to constant wave conditions (defined by a significant wave height, a peak period and a wave direction), constant wind forcing (defined by the wind direction and speed) and varying tidal levels specified from the regional model of Fortunato et al. (2002). The computational grid for ELCIRC has 23000 nodes and will be the basis for the hazard, vulnerability and risk calculations. The calibration and validation of this modeling system in the Aveiro lagoon is described in Vaz et al. (2013).

\subsubsection{Oil hazard quantification}

VOILS (Azevedo et al., 2009, 2014; Azevedo, 2010) is a flexible oil spill model that couples a 2D transport model VELA (Oliveira et al., 2000; Oliveira and Fortunato, 2002), an oil weathering processes model and the circulation model ELCIRC (Zhang et al., 2004) to simulate spill occurrences across estuarine-to-oceanic scales. This modelling system 
uses Eulerian-Lagrangian methods to solve the transport equation (Oliveira and Fortunato, 2002) and considers the major oil weathering processes: spreading, evaporation, water-in-oil emulsification, dispersion, shoreline retention, reposition and dissolution (Azevedo et al., 2014).

With two distinct modes, VOILS can be used to simulate the surface oil slick (2DVOILS) and both the slick and the water column oil dynamics (3D-VOILS). While 2DVOILS solves the surface slick dynamics to simulate oil transport and weathering forced by any compatible circulation model, 3D-VOILS solves additionally the transport of oil in the water column for the dispersed and dissolved oil through the hard coupling of the transport and transformation model (2D-VOILS) with the hydrodynamic model SELFE (Zhang and Baptista, 2008).

The oil spill simulations were forced by the set of 192 hydrodynamic simulations described in detail in den Boer et al. (2014). These hydrodynamic simulations were used to force spills at six locations (Fig. 6), whose probabilities of occurrence were defined by the Port of Aveiro authorities (Table 1), based on their knowledge of the region. Simulations start at three distinct phases of the tide (high tide, low tide and maximum flood) and last for 48 hours (Table 2). To minimize the number of scenarios and based on a preliminary assessment, simulations starting on maximum ebb were neglected, as the plume would rapidly exit the lagoon. Still, this phase of the tide is implicitly included in the evaluation of the hazard, by considering the sum of the probabilities of the other tidal phases to be only $75 \%$ (Table 2 ). Thus, the final hazard scenarios database is constituted by 3456 simulations $(192 \times 6 \times 3)$. Hazard probability maps $(H p)$ are obtained using the following expression, for the total computational grid:

$$
H p(x, y)=\frac{\sum_{i=1}^{n}\left(P_{i} \sum_{j=1}^{m}\left(S_{j} \sum_{k=1}^{l} T_{k} Q(x, y)_{i j k}\right)\right.}{\left(\sum_{i=1}^{n} P_{i}\right)\left(\sum_{j=1}^{m} S_{j}\right)\left(\sum_{k=1}^{l} T_{k}\right)}
$$

where $n=192$ is the number of hydrodynamic simulations, $m=6$ is the number of spill locations, $l=3$ is the number of tidal phases, $P_{i}$ is the occurrence probability associated to the hydrodynamic simulation, $S_{j}$ is the occurrence probability associated to the spill location $j$, and $T_{k}$ is the probability associated to the tidal phase. The variable $Q(x, y)_{i j k}$ is an indicator of the exposure time of oil at each node of the computational grid, calculated from this model simulations. Q ranges between 0 and 1 and is computed as the fraction of time during which oil was present at a particular location.

\section{$<$ FIGURE 6>}

Fig. 6: Location of the six oil spill sites in the Aveiro's Harbour jurisdiction area. 
Table 1 Probabilities associated to the oil spill sites.

\begin{tabular}{cc}
\hline Oil spill sites & Associated probabilities $\left(\boldsymbol{S}_{j}\right)$ \\
\hline Inlet mouth (P1) & $35 \%$ \\
Coastal Fishing Port (P2) & $5 \%$ \\
North Terminal (P3) & $15 \%$ \\
Liquid Bulk Terminal (P4) & $25 \%$ \\
High-Sea Fishing (P5) & $10 \%$ \\
South Terminal (P6) & $10 \%$ \\
\hline
\end{tabular}

Table 2 Probabilities associated to the phases of the tide.

\begin{tabular}{cc}
\hline Phases of the tide & Associated probabilities $\left(\boldsymbol{T}_{\boldsymbol{k}}\right)$ \\
\hline Maximum flood (T1) & $25 \%$ \\
High tide (T2) & $25 \%$ \\
Low tide (T3) & $25 \%$ \\
\hline
\end{tabular}

Table 3 Probabilities associated to the tidal amplitudes.

\begin{tabular}{cc}
\hline Tidal amplitude & Associated probabilities \\
\hline Neap tide & $40.7 \%$ \\
Mean tide & $48.7 \%$ \\
Spring tide & $10.6 \%$ \\
\hline
\end{tabular}

\section{$<$ FIGURE 7>}

Fig. 7: Histogram of tidal ranges at the Aveiro inlet, from a 19 years tidal synthesis. (A1, A2, A3) $=(1.16$, $2.33,3.12) \mathrm{m}$ correspond to the mean tidal amplitudes used in the scenarios simulations for each tidal range. Their associated probabilities of occurrence are $(\mathrm{P} 1, \mathrm{P} 2, \mathrm{P} 3)=(40.7 \%, 48.7 \%, 10.6 \%)$, corresponding to neap, mean and spring tide, respectively.

Eq. 2 provides a unified way to compute the hazard for different conditions. The global hazard is computed by considering all the scenarios ( $n, m$ and $l$ take their maximum values), while conditional probabilities are evaluated by summing over restricted sets of conditions. For instance, the hazard can be computed for specific spill locations (Fig. 8), tidal ranges or wave conditions. 


\section{<FIGURE 8>}

Fig. 8: Hazard map for oil spills in the Liquid Bulk Terminal (P4), for all tidal ranges and wave conditions.

\subsection{Multi-theme Vulnerability Assessment}

The vulnerability assessment presented herein is based on the work described in Oliveira et al. (2013). The methodology is adapted from several other studies (e.g. Pio and Henriques, 2000; MARETEC, 2007; Ng et al., 2008; Castanedo et al., 2009) to produce vulnerability maps, integrating physical, biological and socio-economic aspects. Herein, the methodology of Oliveira et al. (2013) was extended to include the entire lagoon on the vulnerability assessment, not only in terms of its shoreline, but also the whole water body and the intertidal areas. For this purpose, additional improvements were introduced in order to represent the complexity of the exposed elements in the study area.

In order to obtain a Physical Index capable of representing the physical conditions of this lagoon, the overall exposure was included in this analysis, together with tidal conditions, substrate type and shoreline slope, similarly to the Environmental Sensitivity Index (Petersen et al., 2002). Fig. 9 illustrates the methodological approach to estimate the Physical Index, $I_{P}$. Both the main channels of the lagoon and the tidal inlet are considered exposed, while the remaining areas of the Aveiro lagoon are considered to be sheltered. The remaining parameters were obtained according to the guidelines of Petersen et al. (2002).

\section{$<$ FIGURE 9>}

Fig. 9: Flowchart to establish the Physical Index $\left(I_{P}\right)$.

The process to determine the Biological Index, $I_{B}$, is illustrated in Fig. 9. Areas where threatened species exist - fauna and flora - are given the maximum score of 10 . Given the ecological importance of the Aveiro lagoon (wholly classified as a Special Protection Zone of the Natura 2000 Network), the list of threatened species is quite large, including vulnerable, endangered (some critically), endemic and protected species. The remaining areas were classified according to the methodology described by Oliveira et al. (2013), considering: a) the conservation state (Ic) of each water body section according to the current structural and functional status, b) a singularity value $\left(I_{S}\right)$ related with existing legal conservation and protection status, and c) a resilience factor $\left(I_{R}\right)$ which corresponds 
to the ability of local habitats to recover from an oil spill episode. More details about each component of the vulnerability indexes can be found in Oliveira et al. (2013).

\section{$<$ FIGURE 10>}

Fig. 10: Flowchart to establish the Biological Index $\left(I_{B}\right)$.

The Socio-Economic Index, $I_{S E}$, was determined according to the duration of interruption of certain activities occurring in the lagoon. This classification is summarized in Table 4, by adopting the Polmar plan methodology economic index for the activities occurring inside the Aveiro lagoon.

Table 4 The Socio-Economic Index, $I_{S E}$, classification is based on the duration of interruption of activities in case of an oil pollution event (adapted from the French Polmar methodology).

\begin{tabular}{ccc}
\hline \multicolumn{2}{c}{ Socio-Economic Activity } & $\boldsymbol{I}_{\boldsymbol{S E}}$ \\
\hline \multirow{3}{*}{ Recreational } & Bathing/sunbathing & 4 \\
& Sailing & 2 \\
& Wind/Kite surfing & 2 \\
Fesource & Fishing & 5 \\
\hline \multirow{2}{*}{ extraction } & Commercial Fishing & 5 \\
& Aquaculture & 5 \\
\hline \multirow{2}{*}{ Access } & Salt pan & 5 \\
\hline
\end{tabular}

Legend: 1 - Several days; 2 - Several weeks; 3 - Several weeks to months; 4 - Several months to a year; 5 - Over a year.

The Global Vulnerability Index, $I_{G}$, was obtained with the application of Equation (1) and distributed according to the following classes: 0 - Very low; 1 -Low; 2 -Medium; 3 High. The results for the Aveiro lagoon (Fig. 11) highlight the high vulnerability of some intertidal areas.

\section{$<$ FIGURE 11>}

Fig. 11: Global vulnerability index map $\left(I_{G}\right)$. 


\subsection{Oil spill risk computation}

Oil spill risk was determined at each point of the Aveiro lagoon grid based on its probability to be contaminated with oil, the oil exposure time, and the physical, biological and socio-economic vulnerability to oil.

The mathematical expression which quantifies the oil spill hazard in the lagoon environment (Eq. 2) considers the oil exposure time and is the basis for the development of ten hazard probability maps: one map for each spill site and tidal phase, and one map resulting from the sum of probabilities of all previous maps.

The oil risk maps were obtained by multiplying each hazard dataset by each vulnerability dataset, and mapped in an interval between 0 and 100. Although the resulting values vary theoretically between 0 and 100, they are mostly concentrated in the lower range of this interval: the maximum value obtained for this product in the Aveiro lagoon was 61.7. Hence, a Normalized Risk index was defined as:

$$
\text { Normalized risk }=\left(\frac{\text { Risk }}{100}\right)^{1 / 4}
$$

The normalized risk values, that range between 0 and 1, were grouped into 5 classes with the following intervals and designations: [0.0, 0.2[ - Very low; [0.2, 0.4[ - Low; [0.4, 0.6[ - Medium; [0.6, 0.8[ - High; and [0.8, 1.0] - Very high.

\subsection{Mapping and analysis of risk}

To provide the Aveiro Port authorities access to the oil risk management products, a customized WebGIS tool for enhanced oil spill risk assessment and emergency response in coastal areas was developed (Oliveira et al., 2014). This platform was tailored for joint access to both risk and emergency products: a detailed risk assessment through risk maps and related georeferenced information (hazard, vulnerability, risk); and the visualization of georeferenced oil spill plume evolution predictions and oil retention maps, produced by a real-time oil spill forecasting system, and the oil spill response plan.

The risk interface provides access to the database of oil scenarios defined in the hazard analysis through georeferenced products, with a flexible user-defined filtering and the detailed results of the vulnerability analysis (both total and specific vulnerability maps). Based on these inputs, the interface supports a detailed analysis of risk, allowing the identification of the critical elements responsible for a specific risk value or class. By doing so, this platform effectively supports the necessary planning activities to improve risk management in the Aveiro lagoon. Further details on the interface technology are presented in Jesus et al. (2013) and Oliveira et al. (2014). 
The risk analysis was conducted along the several themes controlling risk in the Aveiro lagoon, taking advantage of the individualization of forcing factors provided by the proposed risk methodology. Hence, risk is analyzed for distinct spill sites, tidal phases and types of vulnerability.

\section{$\underline{\text { Oil spill sites }}$}

The downstream sector of the Mira channel (near the P2 spill site) is the area most often affected by spills from almost all sites (except for P6), recording High and Very high risk. In contrast, the more peripheral areas of the Aveiro lagoon, which correspond to the upstream sectors of channels, exhibit Very low to Low risk (Fig. 12). The central zone of the Aveiro lagoon is in general significantly affected for the various scenarios for each oil spill site, with Medium to Very High risk. The location of the oil spill sites, in particular in the central zone of Aveiro lagoon, and the hydrodynamic conditions associated are possible aspects that can justify such results.

The risk associated to oil spills that occur in sites P1, P3, P4 and P5 can be very large (categories High risk and Very high risk) in areas far away from the spill location, illustrating the large tidal excursion of the slicks in the Aveiro lagoon (Fig. 12). This effect stems mostly from the chosen oil spill sites being close to the tidal inlet that connects the main channels of the lagoon to the sea. Thus, these sites are exposed to the strong hydrodynamics conditions, resulting in a greater potential for the advection of the oil. In contrast, oil spills originating in confined locations (P2 and P6) only lead to High and Very high risk close to the corresponding oil spill sites (Fig. 12).

Among the first set of sites, P1 and P4 contribute the most to areas with High and Very High risk in the northern region of the Aveiro lagoon (Fig. 12). This result is due to their location being close to the tidal inlet.

The risk maps generated for the combination of all spill locations (Fig. 13) appear blurred compared to those generated for a single location (Fig. 12). Indeed, the former exhibit a larger area with low to moderate risk, but a smaller area with high and very high risk. This behavior shows that the approach proposed herein transforms the additional information provided by the user (the location of the spill in this case) into clearer maps, thereby pinpointing the locations where interventions are required and narrowing down the course of action to the managers.

\section{<FIGURES 12A, 12B, 12C, 12D, 12E, 12F >}

Fig. 12: Risk maps for each spill location considering the global vulnerability index. A - Inlet mouth; B Coastal Fishing Port; C - North Terminal; D - Liquid Bulk Terminal; E - High-Sea Fishing; F - South Terminal. 


\section{Tidal phase}

The effect of the tidal phase on the risk distribution in the lagoon is small. The areas affected are similar for all tidal phases, with slightly larger values for maximum flood (T1, Fig. 13) and slightly smaller values for the high tide phase (T2).

\section{$<$ FIGURE 13>}

Fig. 13: Risk map for maximum flood phase considering the global vulnerability index.

\section{Vulnerability source/type}

Socio-economic aspects are the most relevant for oil risk in the Aveiro lagoon, as illustrated by the risk maps produced with the socio-economic index. Conversely, risk maps produced with the physical index show the smallest values (Fig. 14).

The risk associated to the physical vulnerability is larger in intertidal zones and confined areas such as the North Terminal and small and narrow channels of the Aveiro lagoon (Fig. 14B). Some of these areas coincide with the largest risk classes based on biological criteria because intertidal flats tend to be relevant habitats for many species (Fig. 14A).

The risk maps strongly reflect the vulnerability maps. Risk maps for the socio-economic index show that oil spills affect considerably the central zone of the Aveiro lagoon, with extensive areas in the Medium and High risk classes. In contrast, risk maps for the other individual vulnerability indexes indicate that the Mira and Ílhavo channels and the North Terminal are the most affected areas.

\section{<FIGURES 14A, 14B, 14C >}

Fig. 14: Risk maps for each individual vulnerability index considering the Liquid Bulk Terminal as spill location: A - Biological index; B - Physical index; C - Socio-Economic index.

\section{Discussion}

5.1. Risk assessment as a planning and management support tool

Risk assessment outputs can be used not only for emergency planning, but also in support of long-term spatial planning decisions. By understanding the geographical distribution of hazard and vulnerability, planners and decision-makers can ensure the valuation of the local natural and socio-economic resources. Moreover, their decisions are more likely to be accepted by citizens and stakeholders (Tavares and Santos, 2014). 
For instance, in the case of the Aveiro lagoon, the areas with higher vulnerability classes (Fig. 11) are concentrated around the tidal inlet and the port infrastructures due to the concentration of uses and activities in these areas. Together with the location of the most probable spill points, this concentration leads to the highest risk of oil spills in this area.

The choice of locations to implement new socio-economic resources or the viability analysis for the relocation of existing resources should thus be supported by detailed risk analyses such as the one proposed herein. This choice is not an easy task since new locations for existing uses and activities are strongly conditioned by the coastal system geomorphology and dynamics (e.g. bivalve aquaculture depends on water renewal and port infrastructures on water depth, which cannot be guaranteed in the upstream areas of the Aveiro lagoon). Therefore, a planning process with an integrated vision of risk management should consider such alternatives, providing a balanced commitment to reduce the exposure of socio-economic and natural resources to the hazard, while minimizing overlaps and conflicts between them.

Local land managers, who are generally responsible for planning and managing maritime and terrestrial uses and activities, must have an integrated vision of risk management rather than focus merely on emergency response. Unlike risk management prevention and reduction measures, emergency response traditionally follows the bottom-up approach in which local government agencies are expected to plan and mitigate risk. The integrated approach proposed herein, with detailed risk and emergency products side-by-side and available for Aveiro harbour authority, can contribute positively to enhance the current vision for both planning and emergency actions.

Despite all efforts, accidents at sea, with very diverse causes, continue to occur. The technical and scientific research on maritime accident understanding and prevention aims to minimize the risk of maritime accidents, making the sea a safer way for maritime transportation while seeking to minimize the risk of these accidents seriously affecting the marine environment. The proposed methodological framework for oil spill risk is a valuable asset for this purpose and can enhance current approaches by linking highresolution, accurate products in hazard and vulnerability assessments to produce risk products at the necessary scales for coastal management.

\subsection{Contributions to improved support to oil risk management}

Risk analysis is a first step to minimize and manage the risk. Reducing the hazard or the vulnerability can mitigate the risk. In the case of oil spills, mitigation measures can be adopted to prevent oil spills and to promote the adequate planning and management of exposed elements, respectively. Also, the development of more accurate and detailed 
contingency plans and the elaboration of more efficient emergency responses and strategies based on risk maps can help to manage and reduce oil spills risk.

By considering different oil spill locations individually, the risk analysis proposed herein can identify the most serious sources of hazard and provide more accurate and detailed information to develop contingency plans and implement response plans given that different oil spill locations affect different areas with different risk magnitudes. For each spill site, a greater assertiveness to implement the measures to respond to oil spills is obtained with the proposed methodology, leading to an higher efficiency to fight the oil dispersion. As a consequence, the oil plume can be better contained and more valuable resources are safeguarded.

Through the distinction of different sources/types of vulnerability of the coastal system, it is possible to make a better and efficient planning and management of natural and socioeconomic resources as different resources are affected differently by the oil. In order to protect these resources, the information present in the vulnerability and hazard maps can be used to establish the areas to install the exploration activities, such as aquaculture or recreational activities, or even to exclude their implementation. Resources must preferentially be allocated to areas in which vulnerability indexes are low and simultaneously oil hazard is low. However, if the vulnerability and hazard are high in the same place, these areas must be excluded as future areas to install assets. In the case of the Aveiro lagoon, all resources show major protection to oil spills in more peripheral areas of the lagoon. In addition, physical resources are also safeguarded in the central zone of lagoon.

\section{Conclusions}

An innovative, high-accuracy, quantitative oil risk management system is proposed herein, to enhance the activity of decision makers and emergency response agents in coastal management. Risk is computed in a rigorous, quantitative way, combining a detailed hazard quantification based on the application of a high-accuracy, process-based oil spill model, and a spatially detailed, high-resolution methodology for vulnerability analysis. Each of the system's products is made available to decision makers and emergency response agents through a WebGIS portal, that serves as a single point of access to both emergency-driven results (such as forecasts of oil spill plumes originating from predefined locations) and risk management maps and its base constituents (hazard and vulnerability maps).

Regarding hazard quantification, the oil model used herein, VOILS, provides in particular a detailed approach to the oil retention and resuspension processes in intertidal areas, accounting for specific bottom characteristics and oil type, and guaranteeing oil mass 
conservation and a rigorous accountability for oil in water and in the bottom sediments. Vulnerability assessment covers the whole coastal system, including both the margins and the water column, with a specific detail over the tidal flats. This assessment is individualized for the source of vulnerability (physical, ecological and socioeconomic). The combination of details at hazard and vulnerability assessment provides an oil risk management framework that supports management choices. The use of this framework can have a significant impact on coastal planning, including resource allocation, and emergency response priorities. While applied herein for oil risk in estuaries, the methodology is generic and can be extended for other types of spills and other types of aquatic systems.

This new risk assessment methodology was applied to the Aveiro lagoon (Portugal), an economically and ecologically important coastal lagoon of Portuguese west coast. Results show that, for the case study region, the areas most affected are the Mira and Ílhavo channels. Oil tends to be retained for long periods of time in intertidal areas, increasing the risk of contamination of these regions. The risk maps produced for the P1, P3, P4 and P5 oil spill sites present higher risk for the study domain, particularly in in areas far away from the spill location. This result can be explained by the proximity of those spill sites to the tidal inlet that connects the main channels of the lagoon to the sea. Thus, these sites are exposed to the strong hydrodynamics conditions, resulting in a greater potential for the advection of the oil. When oil spills occur during the maximum flood, the rapid intervention must be enlarged to the central zone of the lagoon, since the oil is transported to the upstream areas of the Aveiro lagoon, due to stronger water dynamics. Additionally, the socio-economic and biological vulnerability indexes are high, which translates in an increase of the risk index for these areas. This information is very useful when analyzed together with the risk maps for the individual spill sites.

The system presented herein can provide enhanced information for distinct end-users such as port authorities, aquaculture industry, shellfish industry and recreational organizations about the conditions and water quality of the lagoon in the occurrence of an oil spill disaster.

\section{Acknowledgements}

This work was funded by the Portuguese Foundation for Science and Technology (FCT), research project PAC:MAN - Pollution accidents in coastal areas: a Risk management system (PTDC/AAC-AMB/113469/2009), and by the European Regional Development Fund and INTERREG IV B: Atlantic Area Transnational Programme, research project SPRES-2011-1/168. The first and the seventh authors were funded by FCT through grants SFRH/BPD/73089/2010 and SFRH/BD/82489/2011, respectively. 
The vulnerability indexes where developed by the University of Aveiro's team (Fátima L. Alves and Eduardo R. Oliveira). The historical analysis, the hazard and risk methodologies were developed by Alberto Azevedo, André Fortunato, Bruno Epifânio and Sérgio den Boer, from the Estuaries and Coastal Zones Unit of LNEC. Finally the the web platform development was carried out by the elements of the Information Technology in Water and Environment Research Group of LNEC (Gonçalo de Jesus, João L. Gomes and Anabela Oliveira).

This work also makes use of results produced with the support of the Portuguese National Grid Initiative; more information in https://wiki.ncg.ingrid.pt.

The authors would like to thank Prof. João M. Dias, Leandro Vaz and Luís Miguel Tomás for the support in the hydrodynamic component of the meteocean analysis, the Aveiro Port Authority for the help in defining the oil spill locations and the corresponding occurrence probabilities, and Ricardo Costa for the oil spills historical analysis.

\section{$\underline{\text { References }}$}

Abascal, A.J., Castanedo, S., Gutierrez, A.D., Comerma, E., Medina, R., Losada, I.J., 2007. TESEO, an operational system for simulating oil spills trajectories and fate processes. Proceedings, ISOPE-2007: the 17th International Offshore Ocean and Polar Engineering Conference Lisbon, Portugal. The International Society of Offshore Ocean and Polar Engineers (ISOPE) 3, 1751-1758.

Abascal, A., Castanedo, S., Medina, R., Liste, M., 2010. Analysis of the reliability of a statistical oil spill response model. Marine Pollution Bulletin 60, 2099-2110.

Alves, F., Silva, J., Pereira, C, Sousa, L., 2011. Ten years assessment of ICZM principles applied at a local scale: Ria de Aveiro. Journal of Coastal Research Special Issue 64, 1311-1315.

Andrade, M., Szlafsztein, C., Souza-Filho, P., Araújo, A., Gomes, M., 2010. A socioeconomic and natural vulnerability index for oil spills in an Amazonian harbor: A case study using GIS and remote sensing. Journal of Environmental Management 91, 1972-1980.

Ansell, J., Wharton, F., 1992. Risk: Analysis, assessment, and management. John Wiley \& Sons.

Azevedo, A., 2010. Sistema Integrado de Modelação para Apoio à Prevenção e Mitigação de Acidentes de Hidrocarbonetos em Estuários e Orla Costeira. Lisboa, Portugal: Faculdade de Ciências da Universidade de Lisboa, Ph.D. Thesis, 224 pp (in Portuguese).

Azevedo, A., Oliveira, A., Fortunato, A., Bertin, X., 2009. Application of an Eulerian-Lagrangian oil spill modeling system to Prestige. Proceedings $10^{\text {th }}$ International Coastal Symposium, Journal of Coastal Research, Special Issue 56, 777-781.

Azevedo, A., Oliveira, A., Fortunato, A.B., Zhang, J., Baptista, A.M., 2014. A cross-scale numerical modeling system for management support of oil spill accidents. Marine Pollution Bulletin, 80, 13-147. 
Bertin, X., Oliveira, A., Fortunato, A.B., 2009. Simulating morphodynamics with unstructured grids: description and validation of an operational model for coastal applications. Ocean Modelling, 28,1-3, 75-87.

Booij, N., Ris, R.C., Holthuijsen, L.H., 1999. A third-generation wave model for coastal regions, Part I, Model description and validation. Journal of Geophysical Research, C4, 104, 76497666.

Bruneau, N., Fortunato, A.B., Dodet, G., Freire, P., Oliveira, A., Bertin, X., 2011. Future evolution of a tidal inlet due to changes in wave climate, sea level and lagoon morphology (Óbidos lagoon, Portugal). Continental Shelf Research 31, 18, 1915-1930.

Careem, M., De Silva, C., De Silva, R., Raschid, L., Weerawarana, S, 2006. Sahana: Overview of a Disaster Management System. Proceedings of the International Conference on Information and Automation, 361-366.

Castanedo, S., Juanes, J.A., Medina, R., Puente, A., Fernandez, F., Olabarrieta, M., Pombo, C., 2009. Oil spill vulnerability assessment integrating physical, biological and socioeconomical aspects: Application to the Cantabrian coast (Bay of Biscay, Spain). Journal of Environmental Management 91, 149-159.

Chrastanskya, A., Calliesa, U., Fleetb, D.M., 2009. Estimation of the impact of prevailing weather conditions on the occurrence of oil-contaminated dead birds on the German North Sea coast, Environmental Pollution 157, 1, 194-198.

Christensen, F., Andersen, O., Duijm, N., Harremoes, P., 2003. Risk terminology - a platform for common understanding and better communication. Journal of Hazardous Materials A103, 181-203.

Costa, M., Oliveira, A., Rodrigues, M., Azevedo, A., 2009. Application of parallel, highperformance computing in coastal environmental modeling: Circulation and ecological dynamics in the Portuguese coast. Ibergrid: 3rd Iberian Grid Infrastructure Conference Proceedings, 375-386.

Cutter, S., 1993. Living with risk: The geography of technological hazard. London and NY: Edward Arnold.

Dai, F., Lee, C., Ngai, Y., 2002. Landslide risk assessment and management: an overview. Engineering Geology 64, 65-87.

De-Lange, H., Sala, S., Vighi, M., Faber, J., 2010. Ecological vulnerability in risk assessment A review and perspectives. Science of the Total Environment 408, 3871-3879.

de la Huz, R., Lastra, M., Junoy, J., Castellanos, C., Viéitez, J.M., 2005. Biological impacts of oil pollution and cleaning in the intertidal zone of exposed sandy beaches: Preliminary study of the "Prestige" oil spill. Estuarine, Coastal and Shelf Science 65, 19-29.

den Boer, S., Azevedo, A., Vaz, L., Costa, R., Fortunato, A.B., Oliveira, A., Tomás, L.M., Rodrigues, M., 2014. Development of an oil spill hazard scenarios database for risk assessment. In Green, A.N. and Cooper, J.A.G. (eds), Proceedings $13^{\text {th }}$ International Coastal Symposium (Durban, South Africa), Journal of Coastal Research, Special Issue 70, 539-544. 
Dias, J.M., Lopes, J.F., Dekeyser, I., 2000. Tidal propagation in Ria de Aveiro lagoon, Portugal. Physics and Chemistry of the Earth (B) 25, 369-374.

Dias, J.M., Lopes, J.F., Dekeyser, I., 2001. Lagrangian transport of particles in Ria de Aveiro lagoon, Portugal. Physics and Chemistry of the Earth (B) 26, 721-727.

Dias, J.M., Lopes, J.F., 2006. Implementation and assessment of hydrodynamic, salt and heat transport models: The case of Ria de Aveiro Lagoon (Portugal). Environmental Modelling \& Software 21, 1-15.

Dietrich, J.C., C.J. Trahan, M.T. Howard, J.G. Fleming, R.J. Weaver, S. Tanaka, L. Yu, R.A. Luettich Jr., C.N. Dawson, J.J. Westerink, G. Wells, A.Lu, K. Vega, A.Kubach, K.M. Dresback, R.L. Kolar, C. Kaiser, R.R. Twilley, 2012. "Surface trajectories of oil transport along the Northern Coastline of the Gulf of Mexico", Continental Shelf Research, 41, 17-47.

Douglas, J., 2007. Physical vulnerability modelling in natural hazard risk assessment. Natural Hazard and Earth System Sciences 7, 283-288.

EcoRA, 2013. Environmental risk assessment of marine activities. Available: http://www.vliz.be/wiki/Environmental_risk_assessment_of_marine_activities [Accessed 22 July 2014]

Eide, M., Endresen, O., Breivik, O., Brude, O., Ellingsen, I., Roang, K., Hauge, J., Brett, P., 2007. Prevention of oil spill from shipping by modelling of dynamic risk. Marine Pollution Bulletin 54, 1619-1633.

Fernandes, R., Braunschweig, F., Lourenço, F., and Neves, R.: Combining operational models and data into a dynamic vessel risk assessment tool for coastal regions, Ocean Sci. Discuss., 12, 1327-1388, doi:10.5194/osd-12-1327-2015, 2015.

Field, B., Field, M., 2009. Environmental economics: an introduction. McGraw-Hill, New York, p. 493.

Fortunato, A.B., Pinto, L., Oliveira, A., Ferreira, J., 2002. Tidally-generated shelf waves off the western Iberian coast. Continental Shelf Research 22, 14, 1935-1950.

Fortunato, A.B., Rodrigues, M., Dias, J.M., Lopes, C., Oliveira, A., 2013. Generating inundation maps for a coastal lagoon: a case study in the Ria de Aveiro (Portugal). Ocean Engineering 64, 1: 60 - 71.

Fortunato, A.B; Nahon, A.; Dodet, G.; Pires, A.R.; Freitas, M.C.; Bruneau, N.; Azevedo, A.; Bertin, X.; Benevides, P.; Andrade, C.; Oliveira, Anabela. 2014. Morphological evolution of an ephemeral tidal inlet from opening to closure: The Albufeira inlet, Portugal, Continental Shelf Research 73: 49 - 63.

Fortunato, A.B., Oliveira, A., Rogeiro, J., Costa, R.T., Gomes, J.L., Li, K., Jesus, G., Freire, P., Rilo, A., Mendes, A., Rodrigues, M., Azevedo, A., (in press). Operational forecast framework applied to extreme sea levels at regional and local scales. Journal of Operational Oceanography. 
Garcia, D., Bruschi, D., Cumo, F., Gugliermetti, F., 2013. The Oil Spill Hazard Index (OSHI) elaboration. An oil spill hazard assessment concerning Italian hydrocarbons maritime traffic. Ocean \& Coastal Management 80, 1-11.

Greiving, S., Fleischhauer, M., 2006. Spatial planning response towards natural and technological hazards. Geological Survey of Finland, Special Paper 42, 109-123.

Grifoll, M., Jordà, G., Borja, Á., Espino, M., 2010. A new assessment method for water quality degradation in harbour domains, using hydrodynamic models. Marine Pollution Bulletin 60, $69-78$

Iakovou, E., 2001. Na interactive multiobjective model for the strategic maritime transportation of petroleum products: risk analysis and routing. Safety Science 39, 19-29.

IPIECA, 2013. Oil spill risk assessment and response planning for offshore installations. Final report, p. 152.

ISO, 2009. Risk assessment - Risk assessment techniques. ISO 31010:2009.

ISO, 2009. Risk management - vocabulary. ISO Guide 73:2009.

Jesus, G., Santos, M.A., Fernandes, J.P., 2010. SAGE-B: A dynamic dam-break flood emergency management system, Disaster Management 2009, New Forest, Unit Kingdom, 119-131.

Kingston, P., 2002. Long-term environmental impact of oil spills. Spill Science \& Technology Bulletin 7, 53-61.

Kleissen, F., Arentz, L., Reed, M., Johansen, O., 2007. Marine environmental risk assessment system: Conceptual design and preliminary demonstration for the Dutch continental shelf. Delf Hydraulics Report, p. 46.

Lahr, J., Kooistra, L., 2010. Environmental risk mapping of pollutants: State of the art and communications aspects. Science of the Total Environment 408, 3899-3907.

Lee, M., Jung, J, 2013. Risk assessment and national measure plan for oil and HNS spill accidents near Korea. Marine Pollution Bulletin 73, 339-344.

Liu, R., Borthwick, A., Lan, D., Zeng, W., 2013. Environmental risk mapping of accidental pollution and its zonal prevention in a city. Process Safety and Environmental Protection 91, 397-404.

Liu, T., Sheng, Y.P., 2014. Three dimensional simulation of transport and fate of oil spill under wave induced circulation. Marine Pollution Bulletin 80, 148-159.

Lopes, J.F., Dias, J.M., 2007. Residual circulation and sediment distribution in the Ria de Aveiro lagoon, Portugal. Journal of Marine Systems 68, 507-528.

MARETEC, 2007. Atlas Costeiro de Portugal Continental. Emergency Response to Coastal Oil. Technical Report. Porto, Portugal.

Ng, T.F., Vijayan, V.R., Chow, W.S., Sulaiman, A., 2008. Assessment of oil spill vulnerability of Southwest Pulau Pinang shoreline. Bulletin of the Geological Society of Malaysia 54, 123131. 
Oliveira, A., Fortunato, A.B., 2002. Toward an oscillation-free, mass conservative, EulerianLagrangian transport model. Journal of Computational Physics 183, 142-164.

Oliveira, A., Fortunato, A.B., Baptista, A.M., 2000. Mass balance in Eulerian-Lagrangian transport simulations in estuaries. Journal of Hydraulic Engineering 126 (8), 605-614.

Oliveira, E.R., Silveira, B., Alves, F.L., 2013. Support mechanisms for oil spill accident response in coastal lagoon areas (Ria de Aveiro, Portugal). Journal of Sea Research 93, 112-117.

Olita, A., Cucco, A., Simeone, S., Ribotti, A., Fazioli, L., Sorgente, B., Sorgente, R., 2012. Oil spill hazard and risk assessment for the shorelines of a Mediterranean coastal archipelago. Ocean \& Coastal Management 57, 44-52.

Penela-Arenaz, M., Bellas, J., Vázquez, E., 2009. Chapter Five: Effects of the Prestige Oil Spill on the Biota of NW Spain 5 Years of Learning. Advances in Marine Biology 56, 365-396.

Petersen, J., Zengel, S., White, M., Lord, C., Planc, C., 2002. Environmental Sensitivity Index Guidelines Version 3.0, National Oceanic and Atmospheric Administration, Technical Memorandum NOS OR\&R 11,. Seatle, Washington, USA.

Picado, A., Dias, J.M., Fortunato, A.B., 2010. Tidal changes in estuarine systems induced by local geomorphologic modifications. Continental Shelf Research 30, 1854-1864.

Pine, J., 2009. Natural hazards analysis: Reducing the impact of disasters. CRC Press, Taylor \& Francis Group, p. 285.

Pio, S., Henriques, A.G., 2000. O estado ecológico como critério para a gestão sustentável das águas de superficie. Proceedings of the Congresso da Água 2000. Lisbon, Portugal, pp. 115.

Rao, P., Raghavan, K., 1996. Hazard and risk potential of chemical handling at ports. Journal of Loss Prevention in the Process Industries 9, 199-204.

Rodrigues, A.S., M.A. Santos, A.D. Santos, F. Rocha, 2002. Dam-Break Flood Emergency Management System, Water Resources Management 16, 489-503.

Ronza, A., Carol, S., Espejo, V., Vílchez, J.A., Arnaldos, J., 2006. A quantitative risk analysis approach to port hydrocarbon logistics. Journal of Hazardous Materials A128, 10-24.

Sanchez, S. 2008. Risk assessment in ports, Lectures of the Risk Management in Civil Engineering Course.

Available: http://riskmanagement.lnec.pt/pdf/papers/Nov21_apresentacoes/24_text_Sanchez.pdf.

Salter, J., 1997. Risk management in a disaster management context. Journal of Contingencies and Crisis Management 5, 60-65.

Santos, C., Michel, J., Neves, M., Janeiro, J., Andrade, F., Orbach, M., 2013. Marine spatial planning and oil spill risk analysis: Finding common grounds. Marine Pollution Bulletin 74, 73-81.

Santos, C., Gonçalves Teixeira, Z., Janeiro, J., Sousa Gonçalves, R., Bjorkland, R., Orbach, M., 2012. The European Marine Strategy: Contribution and challenges from a Portuguese perspective. Mar. Policy 36, 963-968. 
Schwab, J., Topping, K., Eadie, C., Deyle, R., Smith, R., 1998. Planning for post-disaster recovery and reconstruction. Planning Advisory Service report 483/484, p. 346.

Tarrant, M., 1998. Risk communication in the context of emergency management planning: Planning with rather than for communities. Australian Journal of Emergency management 4, 20-21.

Tavares, A.O., Santos, P.P., 2014. Re-scaling risk governanceusing local appraisal and community involvement. Journal of Risk Research, 17:7, 923-949.

Tkalich, P., 2006. A CFD solution of oil spill problems. Environmental Modelling \& Software, 21, pp. 271-282.

Trbojevic, V., Carr, B., 2000. Risk based methodology for safety improvements in port. Journal of Hazardous Materials 71, 467-480.

United Nations/Inter-Agency Secretariat of the International Strategy for Disaster Reduction (UN/ISDR), 2004. Living with risk - A global review of disaster reduction initiatives. New York and Geneva, p. 457.

van Dorp, J., Merrick, J., 2011. On a risk management analysis of oil spill risk using maritime transportation system simulation. Annals of Operations Research 187, 249-277.

van Westen, C.J., van Asch, T., Soeters, R., 2006. Landslide hazard and risk zonation - why is it still so difficult?. Bulletin of Engineering Geology and the Environment 65, 167-184.

Vaz, L., Plecha, S., Dias, J.M., 2013. Coastal waves regime influence on Ria de Aveiro inlet dynamics. Journal of Coastal Research, Special Issue 65, 1605-1610.

Wang, J., Shen, Y., 2010. Modeling oil spills transportation in seas based on unstructured grid, finite-volume, wave-ocean model. Ocean Modelling 35, 332-344.

Xiaoyan, D., Xiaofei, L., 2012. Conceptual model on regional natural disaster risk assessment. Procedia Engineering 45, 96-100.

Zhang, Y., Baptista and A.M, Myers, E.P., 2004. A cross-scale model for 3D baroclinic circulation in estuary-plume-shelf systems: I. Formulation and skill assessment. Continental Shelf Research, 24/18. 2187-2214.

Zhang, Y., Baptista, A.M., 2008. SELFE: A semi-implicit Eulerian-Lagrangian finite-element model for cross-scale ocean circulation. Ocean Modelling, 21, 71-96.

Zêzere, J.L., Garcia, R., 2013. Análise do risco a deslizamentos: a matriz de risco. VI National Congress of Geomorphology. Proceedings, Coimbra, 91-95 (in Portuguese).

Zêzere, J.L., Ramos, C., Reis, E., Garcia, R., Oliveira, S., 2008. Perigos naturais, tecnológicos e ambientais na região do Oeste e Vale do Tejo. Inforgeo 22/23, 37-49. 


\section{Figures}

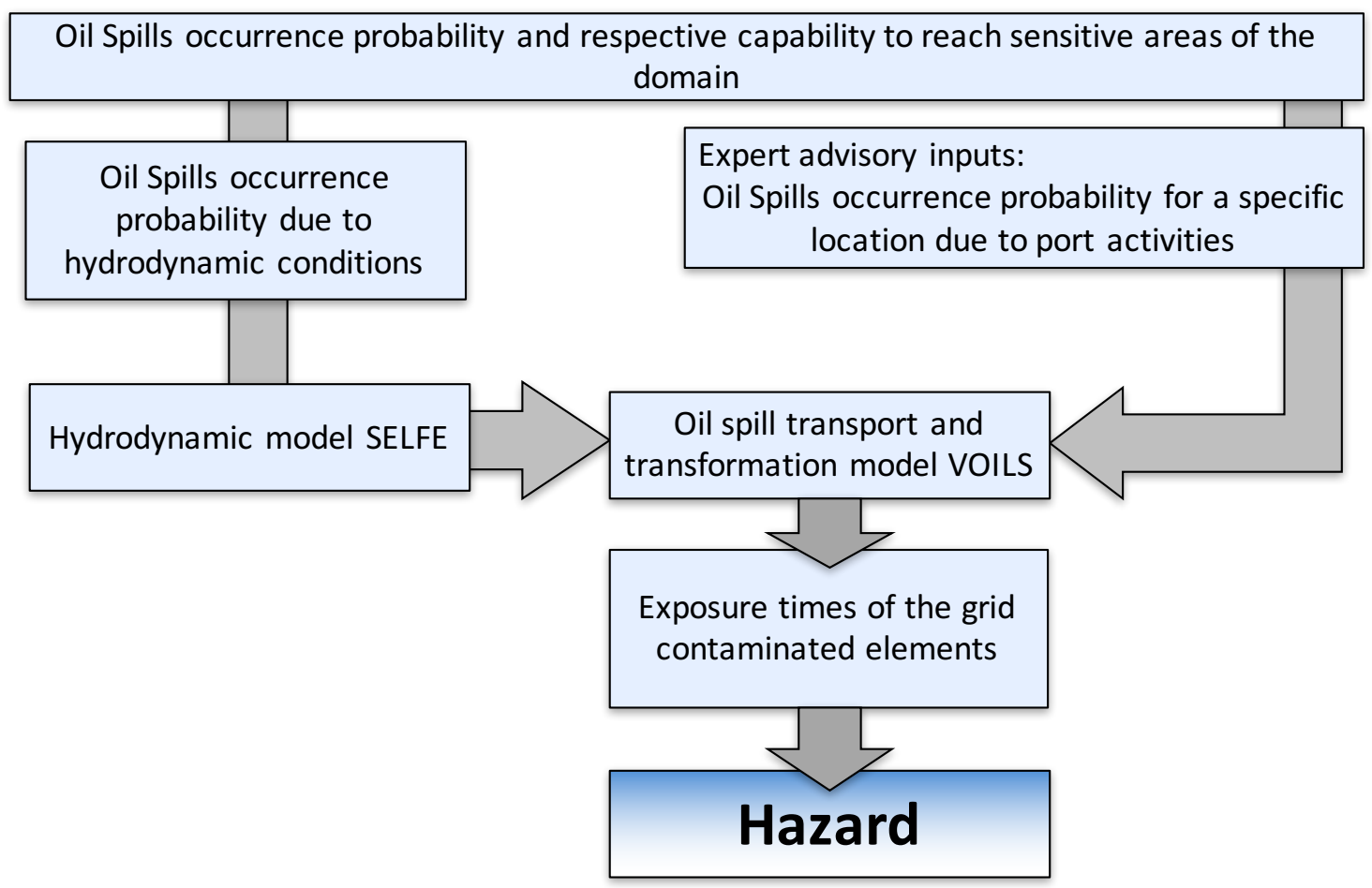

\section{Fig 1}

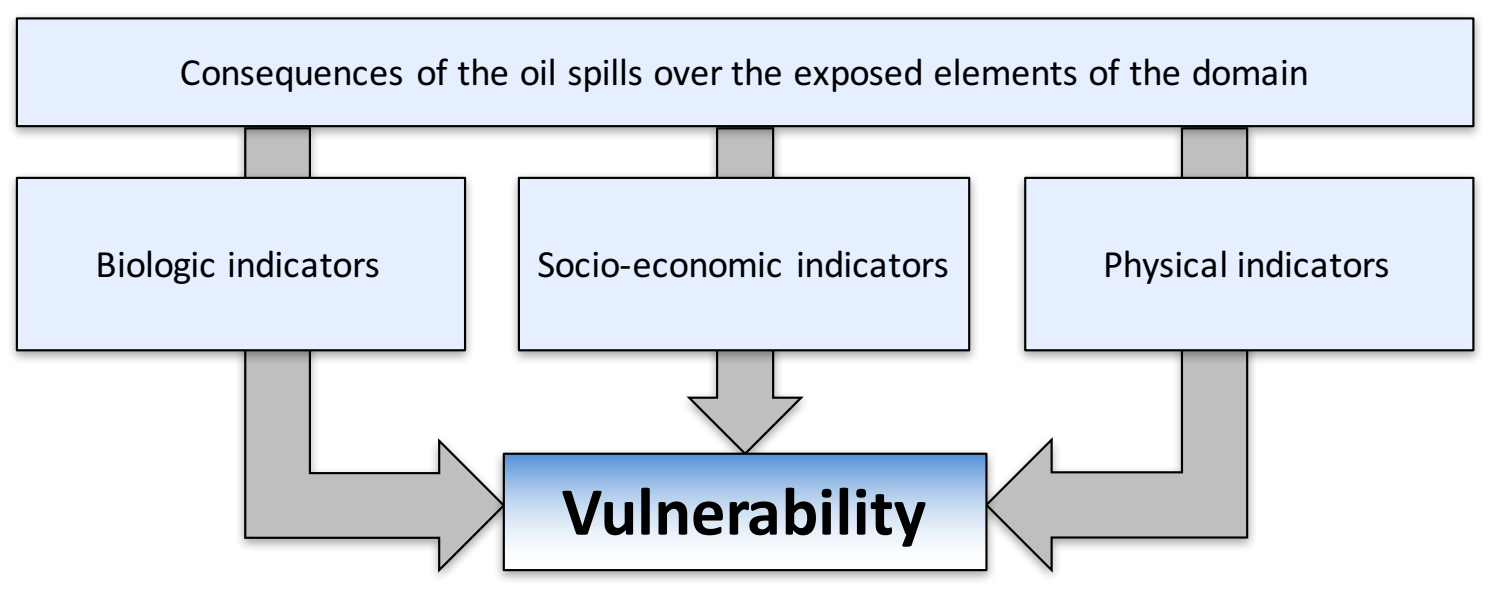

\section{Fig 2}




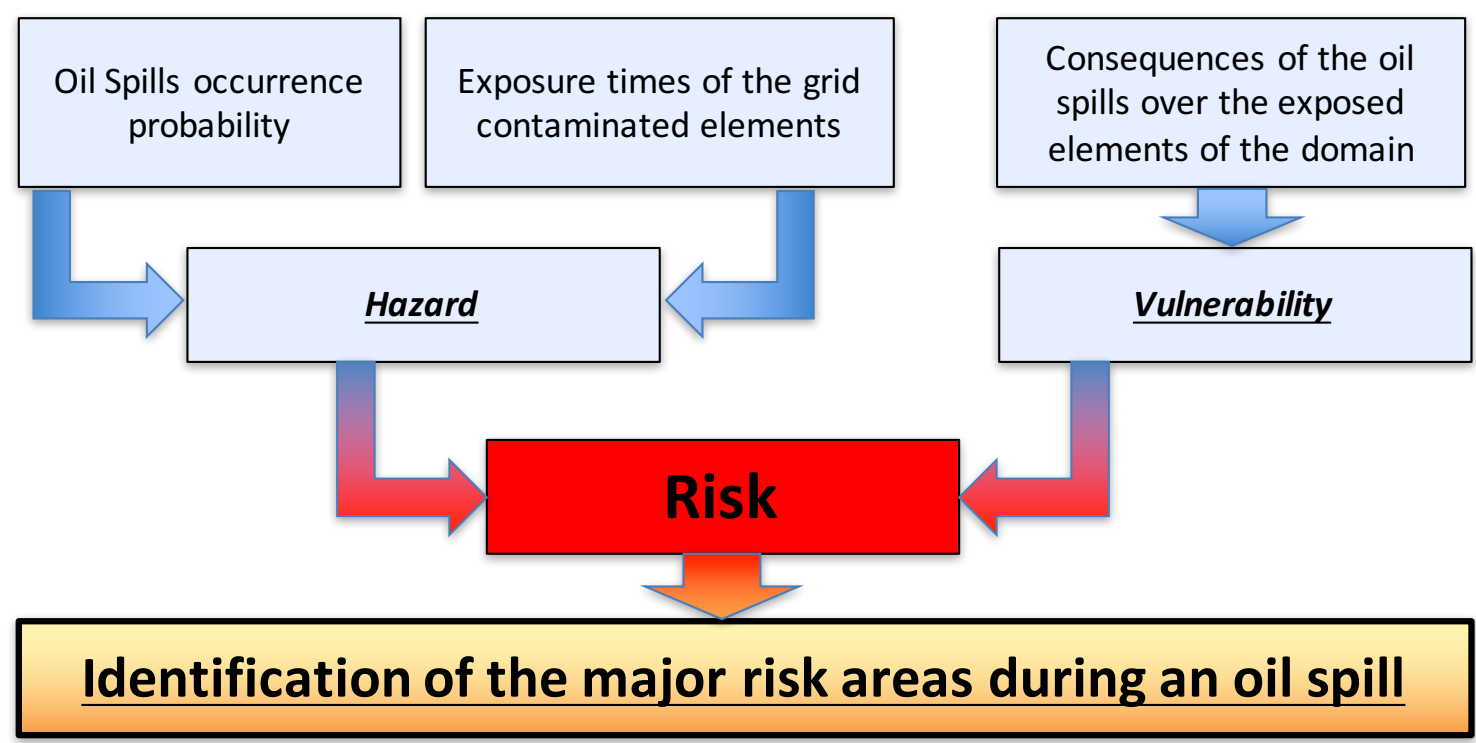

Fig 3 


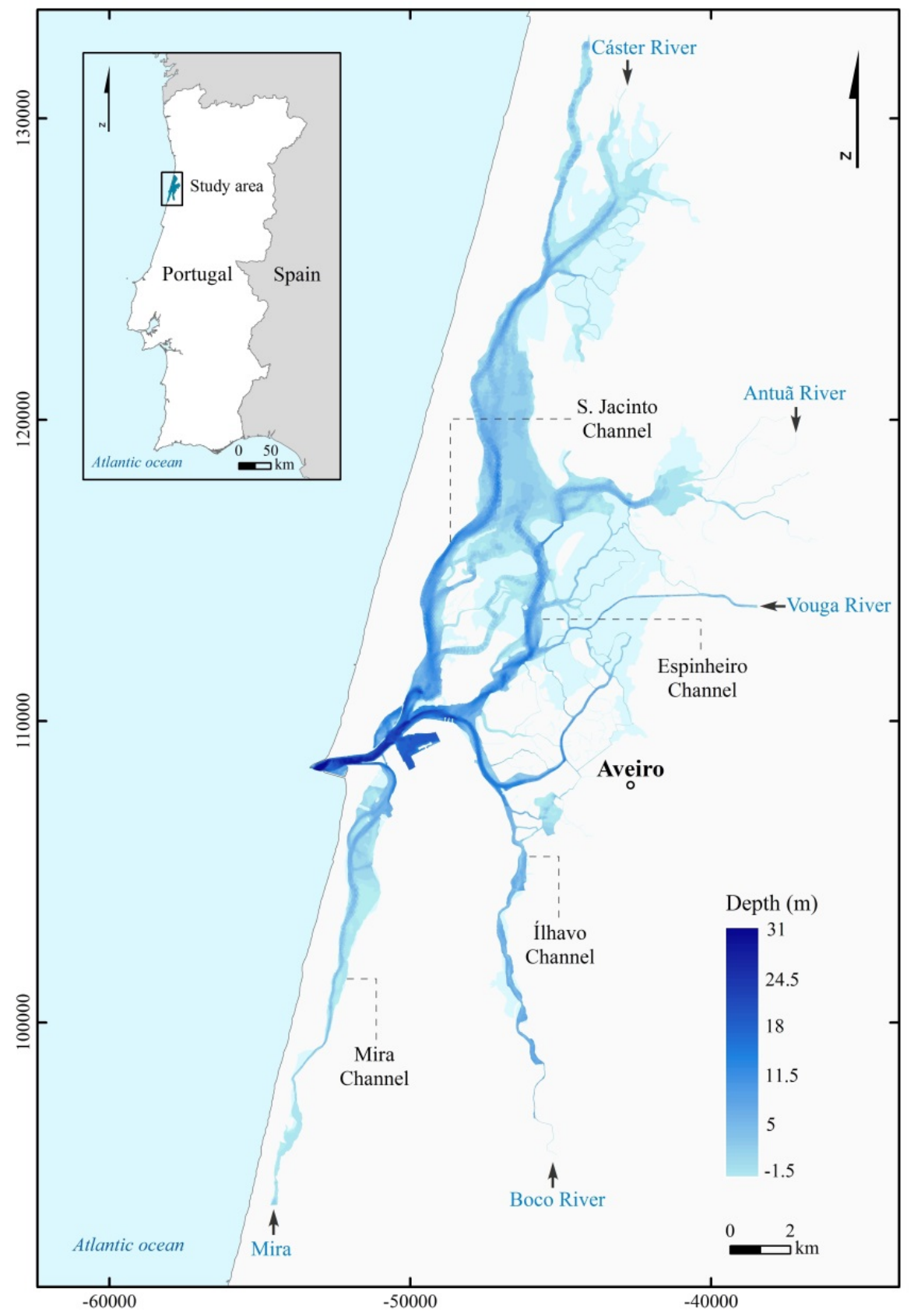

Fig 4 


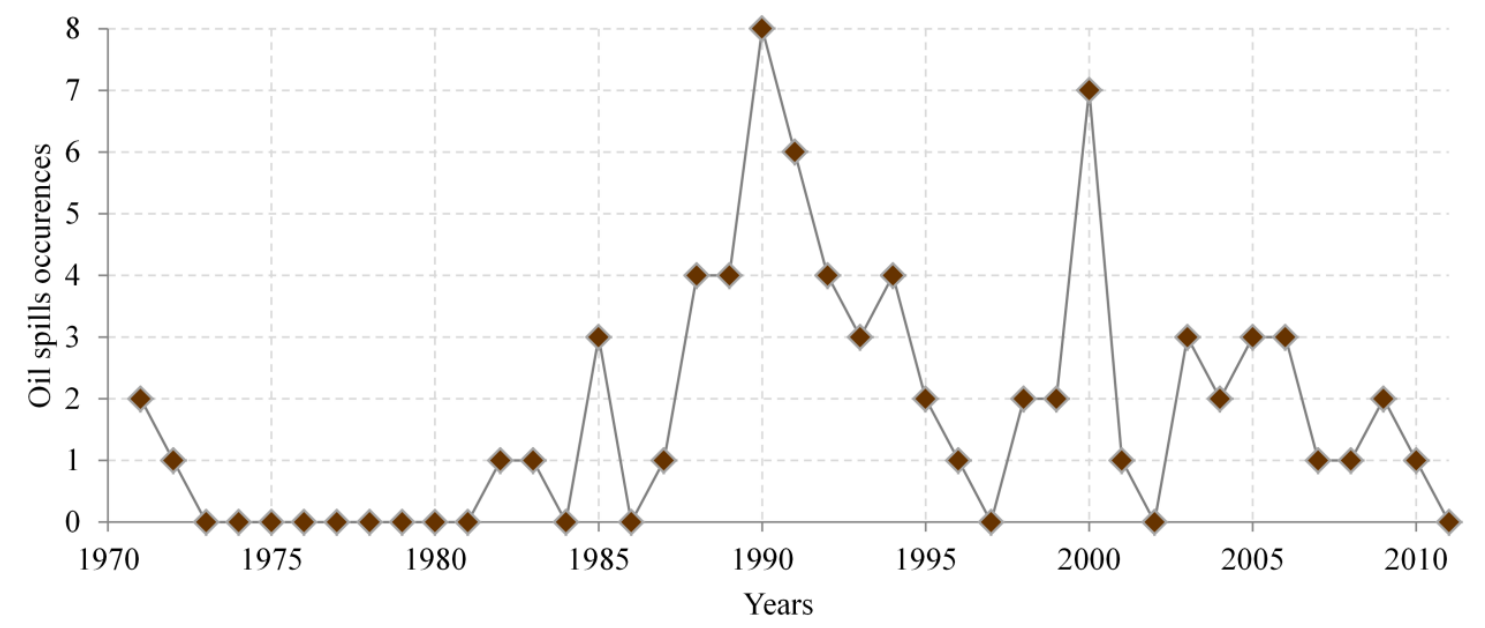

\section{Fig 5}

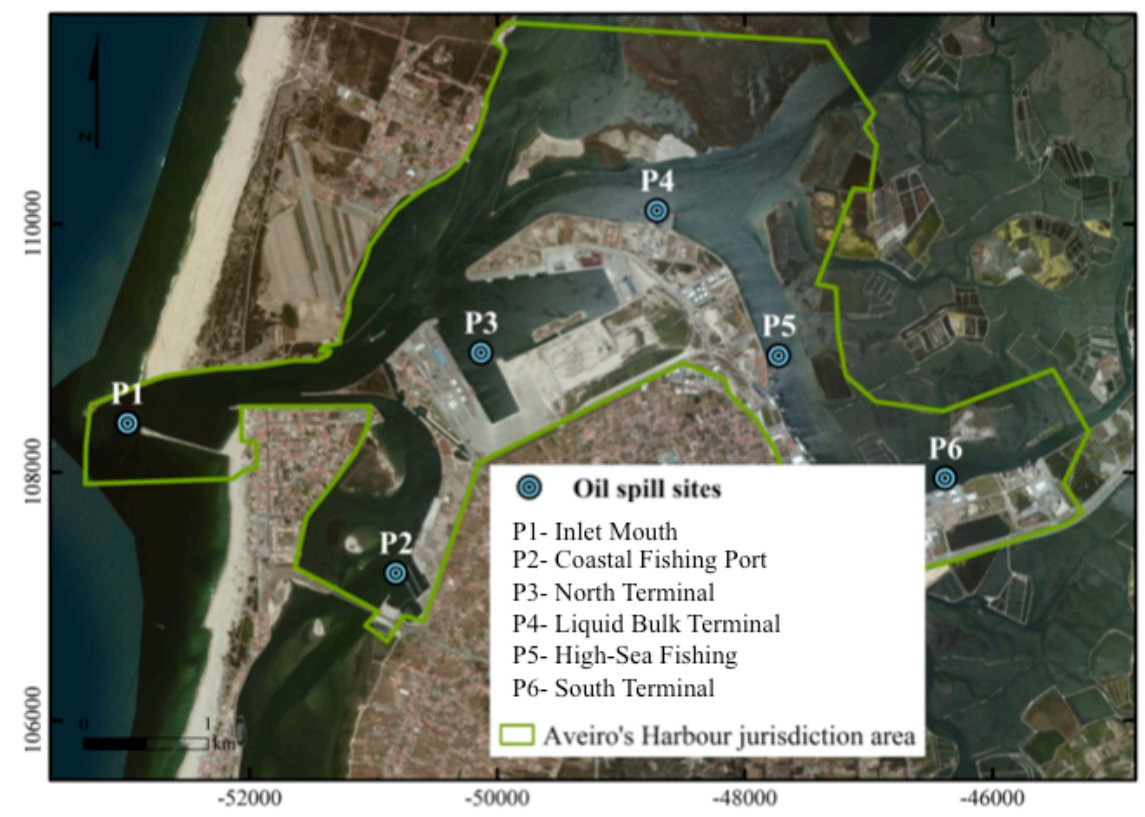

\section{Fig 6}




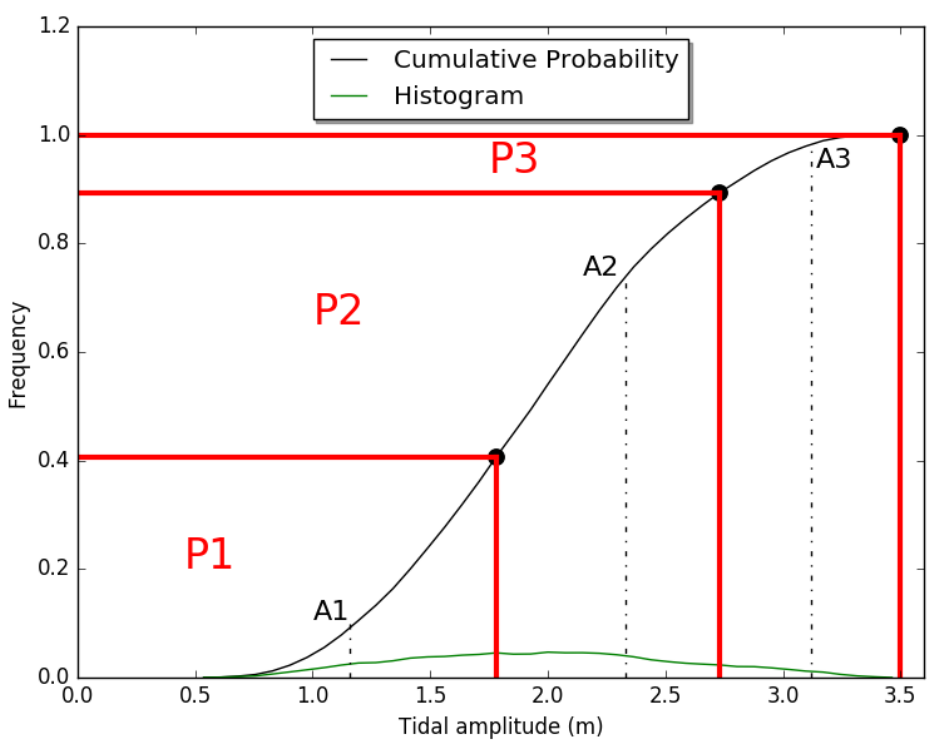

Fig 7 


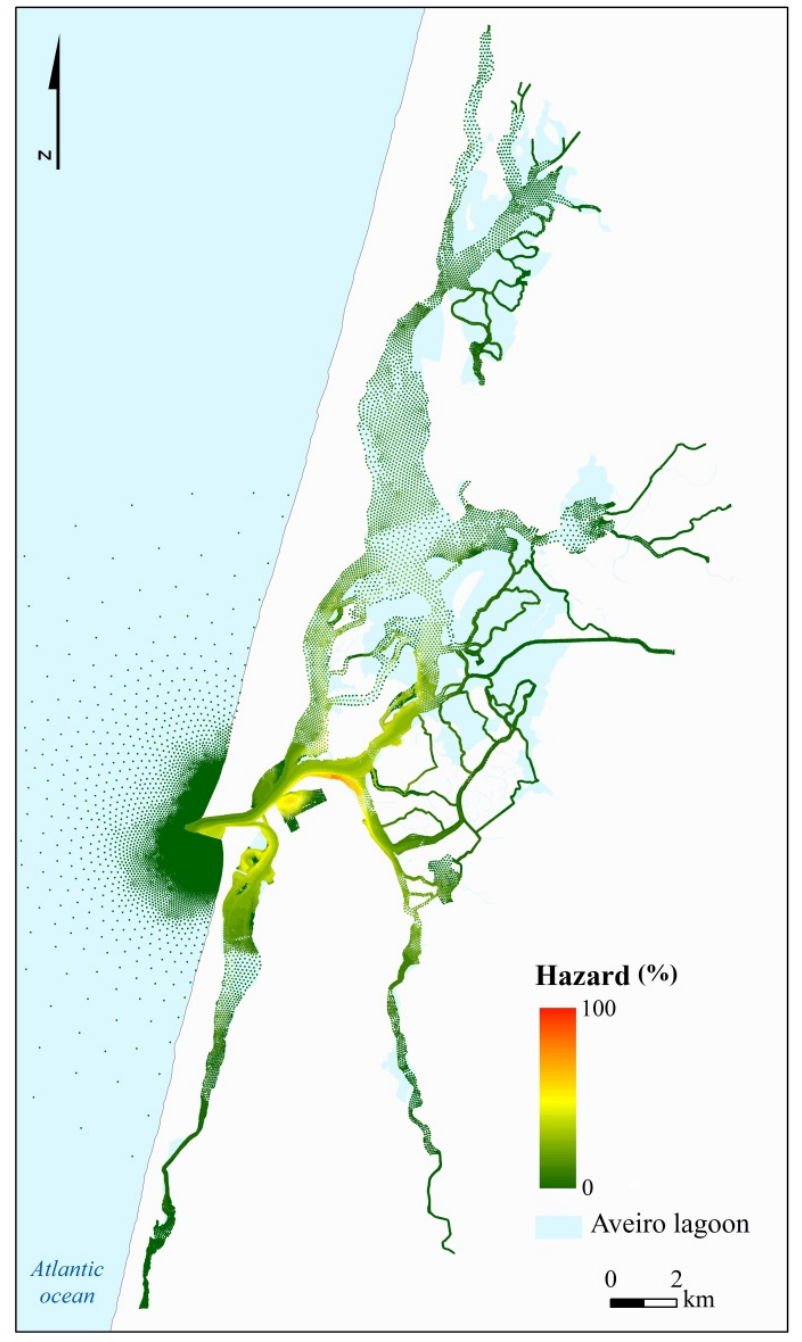

Fig 8 


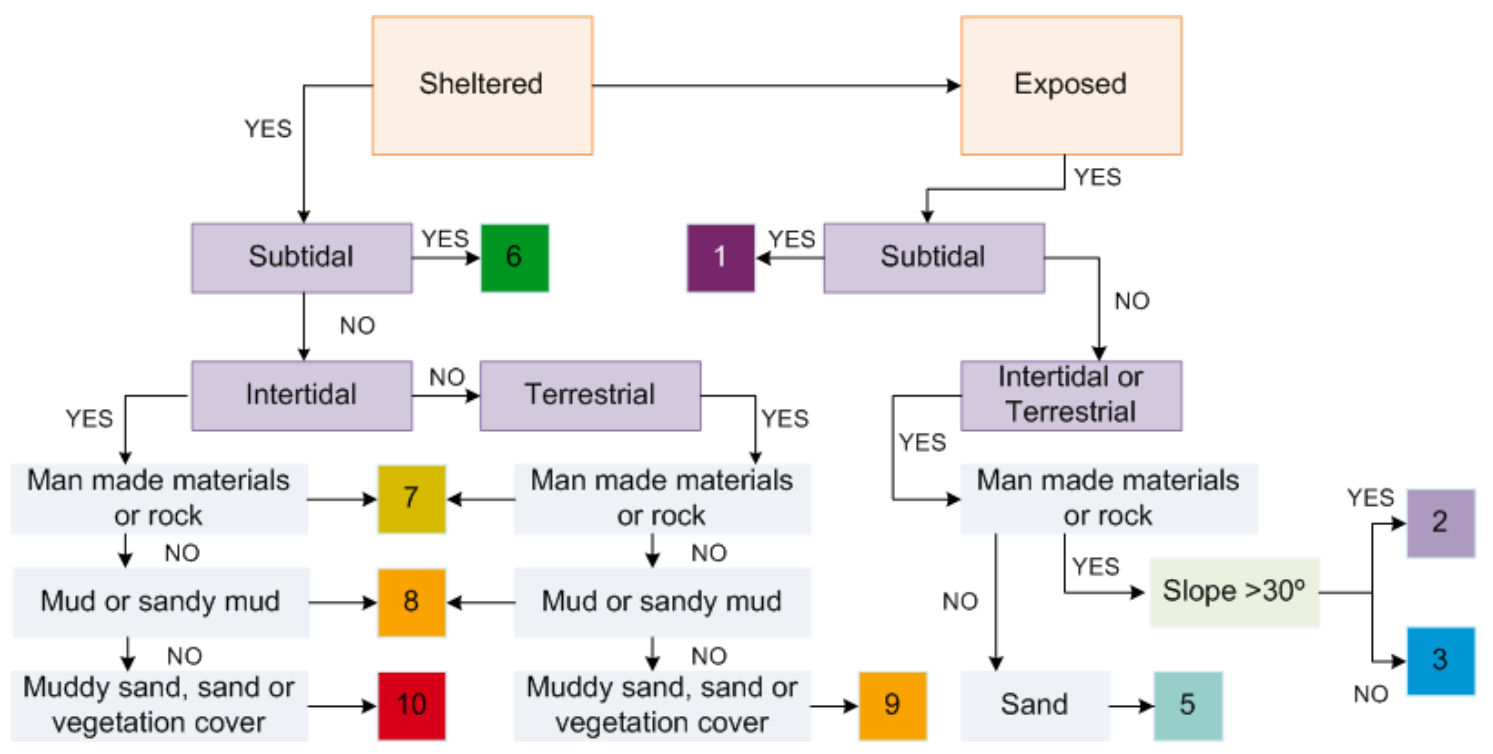

\section{Fig 9}

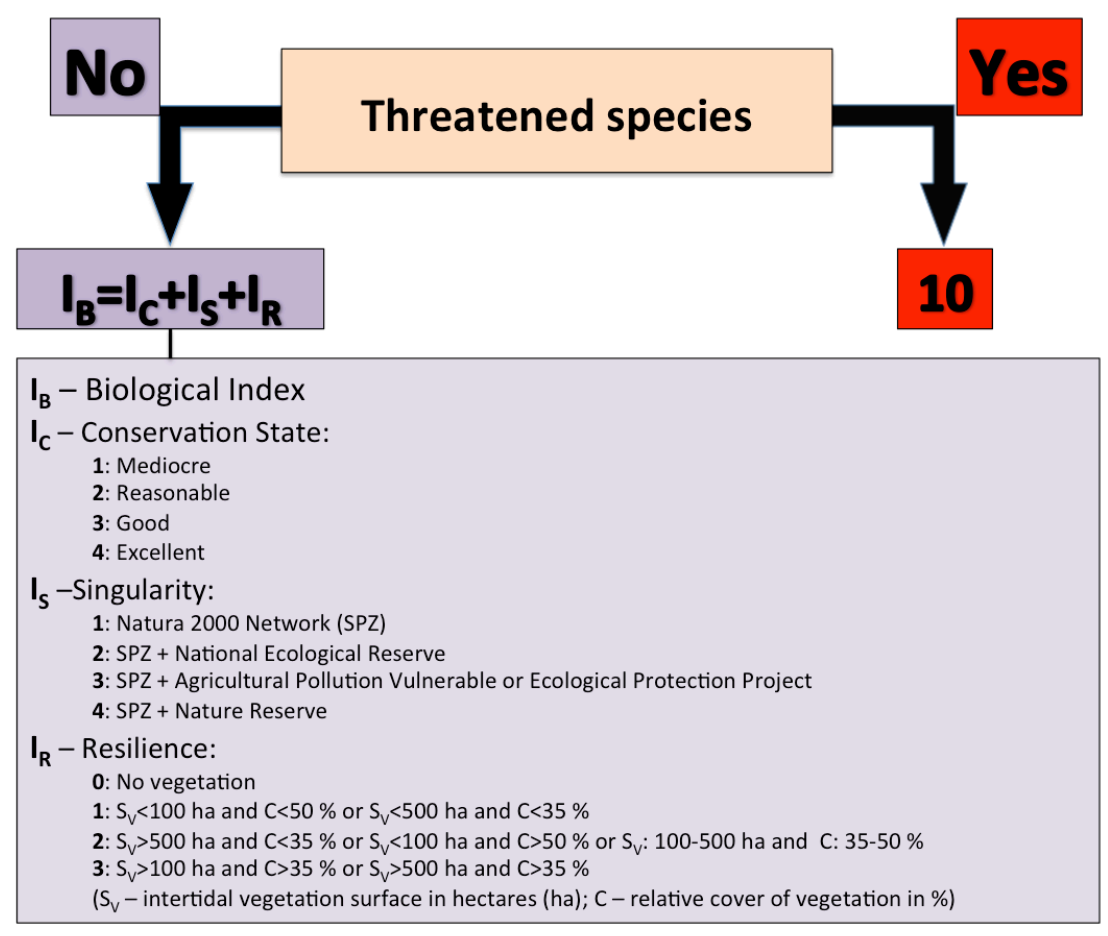

\section{Fig 10}




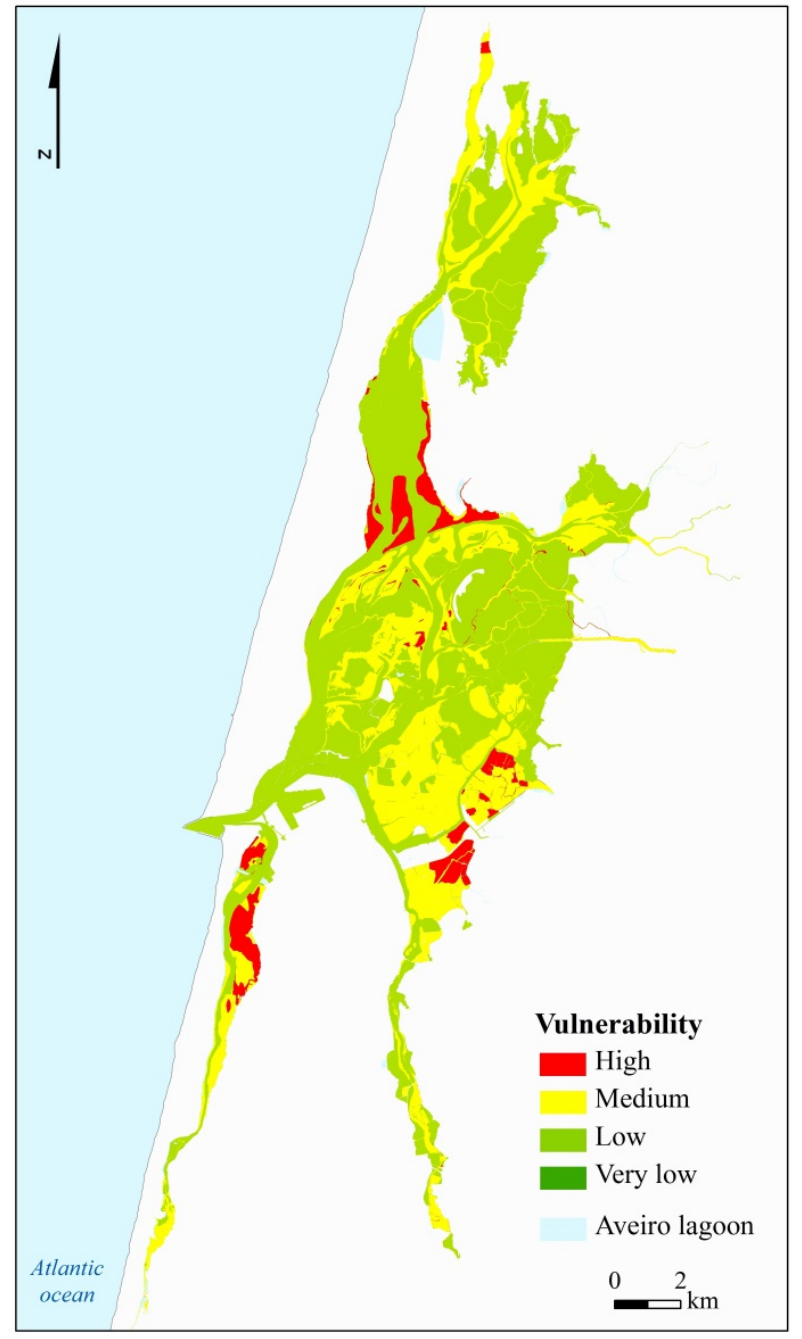

Fig 11 


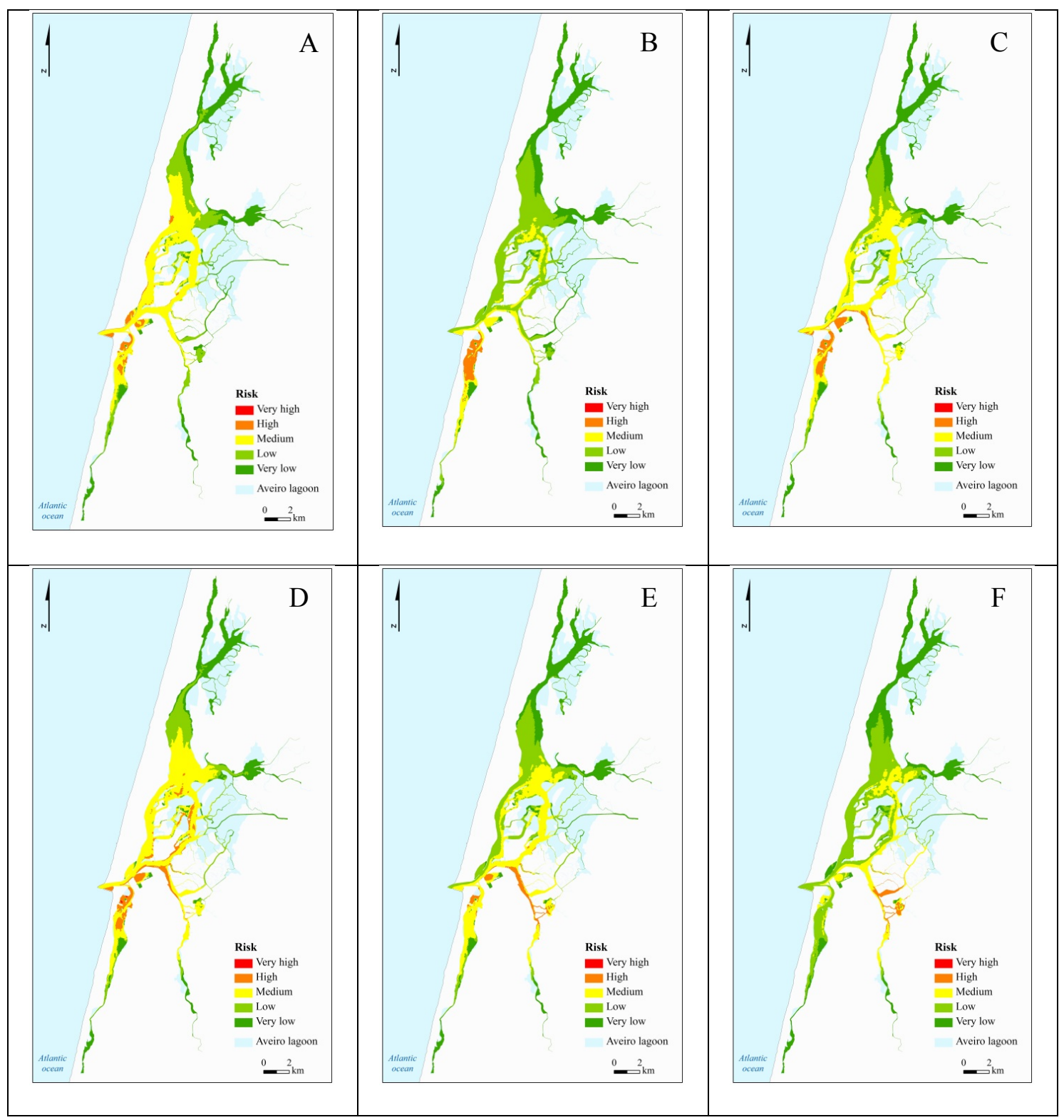

Fig 12A, 12B, 12C, 12D, 12E, 12F 


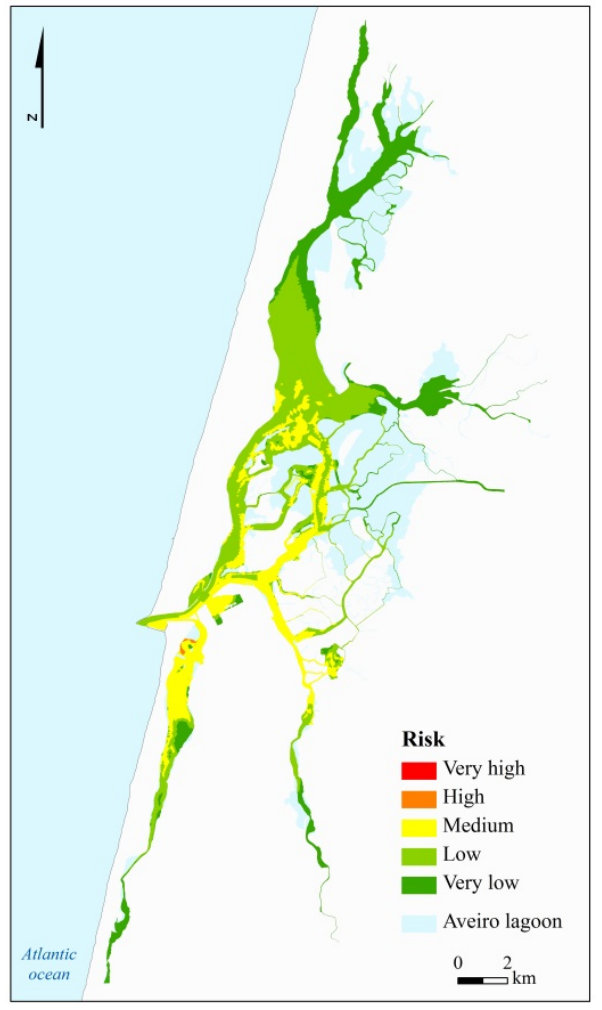

\section{Fig 13}

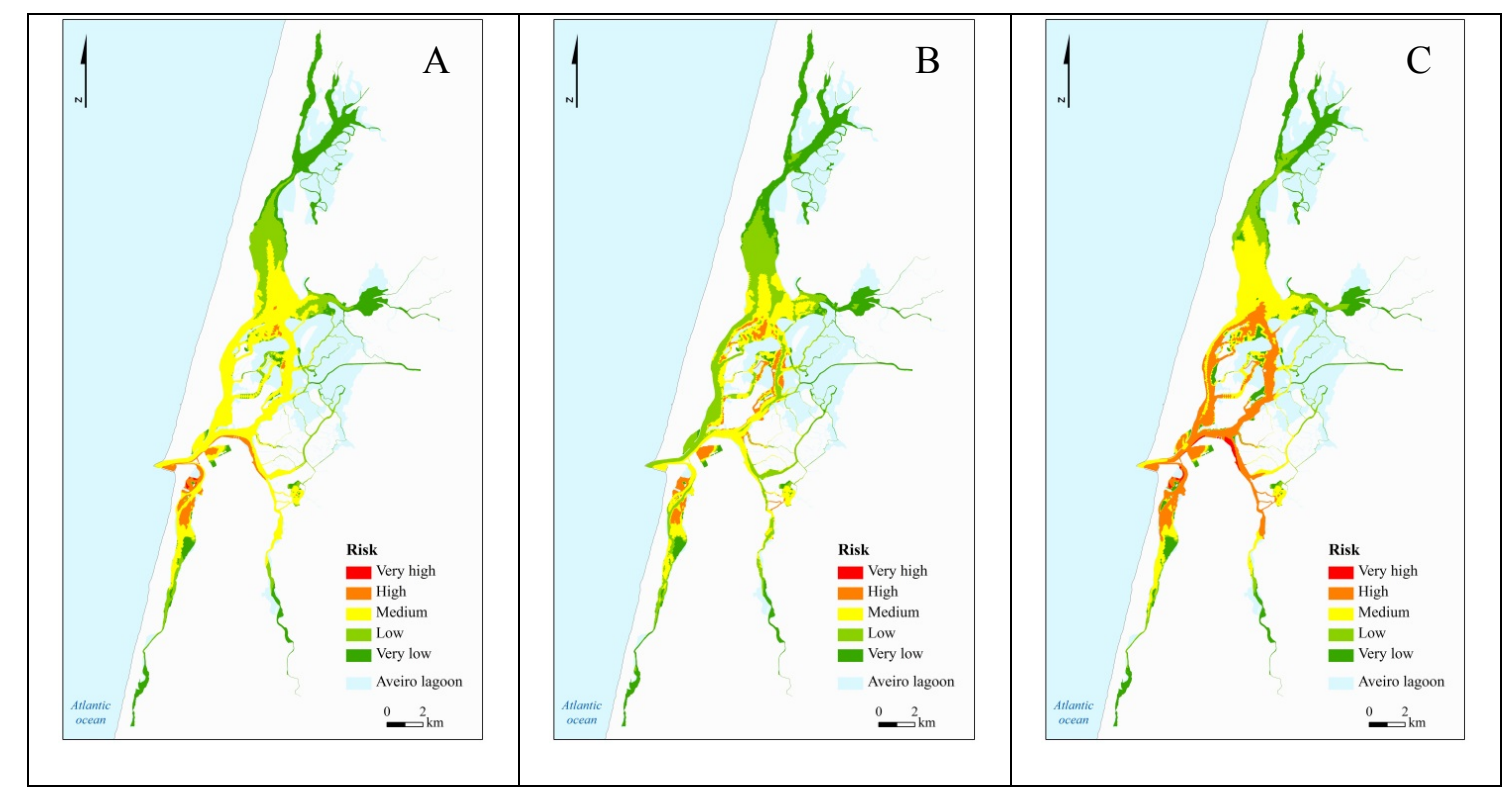

FIG 14A, 14B, 14C 